Bundesgesundheitsbl 2015 · 58:1129-1150 DOI 10.1007/s00103-015-2231-5

Online publiziert: 28. September 2015

c) Springer-Verlag Berlin Heidelberg 2015

Mitteilungen des Arbeitskreises Blut des Bundesministeriums für Gesundheit

\title{
Wissenschaftliche Erläuterungen zur Stellungnahme „Bewertung von Apherese- und Pool- Thrombozytenkonzentraten" des AK Blut vom 31.03.2015
}

\section{Bei der 79. Sitzung des Arbeitskrei- ses Blut am 31. März 2015 wurde folgende Ergänzung zu Stellung- nahme (S 15) verabschiedet:}

\section{Einleitung}

Bei der Versorgung von Patienten mit Thrombozytenpräparaten kommen in Deutschland verschiedene Herstellungsverfahren zum Einsatz. Zur Herstellung von Pool-Thrombozytenkonzentraten (PTK) werden die Thrombozyten aus mehreren Vollblutspenden zusammengeführt (gepoolt), zur Herstellung von Apherese-Thrombozytenkonzentraten (ATK) werden Thrombozyten maschinell von einem Spender gewonnen. Aktuell gibt es eine Diskussion über die Vor- und Nachteile beider Thrombozytenkonzentrate, die auch in der wissenschaftlichen Literatur geführt wird. Unabhängig von der Präparateauswahl (Poolbzw. Apherese-TK) gibt es weitere Diskussionspunkte einer optimalen, evidenzbasierten Therapie mit Thrombozytenkonzentraten: die Indikation (prophylaktische versus therapeutische Transfusion), der Transfusionstrigger und die Dosierung. Ein weiterer zentraler Aspekt der Debatte ist die Risikobewertung von PTK und ATK, insbesondere mit Blick auf Infektionsrisiken. Hierbei sind die Spenderexposition ebenso wie die mit der jeweiligen Spenderpopulation assoziierten $\mathrm{Ri}$ siken zu berücksichtigen. Außerdem ist auch die Frage der Versorgungssicherheit der Patienten mit Thrombozytenkonzentraten und Auswirkungen möglicher Veränderungen der Thrombozytenversor- gung auf die Struktur des Blutspendewesens in Deutschland von Bedeutung.

Die Intensivierung der Diskussion in Deutschland wurde durch ein Urteil des Sozialgerichts für das Saarland vom 19.06.2009 (S23KR100/09) und die Ablehnung der Berufung durch das Landessozialgericht für das Saarland vom 22.08.2012 (L2KR39/09) ausgelöst. In diesem Rechtsstreit ging es um die Kostenerstattung für zwei ATK, die akut im Rahmen eines kardiochirurgischen Eingriffs bei einer Patientin verabreicht wurden. Der Kostenträger hatte die Abrechnung des Zusatzentgeltes mit der Begründung verweigert, dass auch PTK hätten transfundiert werden können. Diese wären aufgrund der unterschiedlichen Vergütungsstruktur im DRG-Entgeltsystem nicht gesondert erstattet, sondern als mit der Fallpauschale abgegolten angesehen worden [1]. Die Klage sowie die Berufung scheiterten, da von Seiten des Gerichts kein Unterschied in der Wirksamkeit beider Präparateformen anerkannt wurde. Ein möglicher Risikounterschied zwischen beiden Produkten wurde in der Urteilsbegründung für bekannte Erreger nicht als erwiesen angesehen, ein möglicher Risikounterschied im Hinblick auf unbekannte Erreger wurde als nicht relevant für die Entscheidung betrachtet. Eine medizinische Notwendigkeit der Applikation von ATK wurde nicht anerkannt. Logistische Gründe für die Verabreichung von ATK (keine PTK im Depot) wurden ebenfalls nicht berücksichtigt, da grundsätzlich derartige Produkte auf dem Markt seien und deren Verfügbarkeit durch das Krankenhaus hätten ermöglicht werden können. Die Gesamtversorgungssicherheit mit TK in Deutschland und die dafür evtl. notwendige Aufrechterhaltung eines dualen Systems sei für die Beurteilung des Einzelfalls unerheblich.

$\mathrm{Zu}$ dem Thema liegen bereits mehrere Stellungnahmen bzw. Gutachten von Fachgesellschaften, z. B. der Deutschen Gesellschaft für Transfusionsmedizin und Immunhämatologie (DGTI) [2], der Arbeitsgemeinschaft der Ärzte staatlicher und kommunaler Bluttransfusionsdienste e. V. (StKB) [3] und des Berufsverbandes Deutscher Transfusionsmediziner e. V. [4] vor.

Primäres Ziel dieser Stellungnahme des AK Blut ist es, Daten zur vergleichenden Risiko-Nutzen-Abwägung und Auswirkungen auf die Versorgung zu bewerten. Wichtige Punkte sind hierbei die Besonderheiten der Herstellung, therapeutische Aspekte, die Wirksamkeit der Präparate, Bewertung von Risiken für unerwünschte Reaktionen bei Transfusionen einschließlich Infektionen, die Versorgungslage und die Perspektive der Spenderinnen und Spender. ATK und PTK werden mit Blick auf diese Punkte vergleichend betrachtet. Ergebnisse aus Literaturrecherchen und eigene Daten werden den einzelnen Punkten zugeordnet und abschließend bewertet. Die Stellungnahme wird Aspekte der Pathogeninaktivierung von TK nicht vertiefen. Hier$\mathrm{zu}$ ist eine separate Stellungnahme des AK Blut in Vorbereitung. 


\section{Herstellung}

Thrombozytenkonzentrate können als Pool-Thrombozytenkonzentrate aus Vollblutspenden oder durch Apherese (Thrombozytapherese oder Multikomponentenspende) hergestellt werden. Für beide Präparatetypen sind in den Hämotherapie-Richtlinien die gleichen Qualitätskriterien vorgegeben [5]: Unter anderem muss der Thrombozytengehalt mindestens $2 \times 10^{11} /$ Einheit betragen, die Restleukozytenzahl muss geringer als $1 \times 10^{6} /$ Einheit sein und die Resterythrozytenzahl darf höchstens $3 \times 10^{9} /$ Einheit betragen.

\subsection{Herstellung von Pool-TK}

PTK können mit zwei Methoden hergestellt werden: Bei der Buffy coat (BC)Methode wird die Vollblutspende nach einer schnellen Zentrifugation in Komponenten aufgeteilt. Der gewonnene BC wird anschließend langsam zentrifugiert und das TK wird aus dem Überstand gewonnen. Alternativ wird die Vollblutspende langsam zentrifugiert und bei der Komponentenauftrennung wird ein plättchenreiches Plasma (PRP) gewonnen, das wiederum durch schnelle Zentrifugation und Resuspension der Thrombozyten zum TK wird [6, 7]. Die in Deutschland eingesetzten PTK werden ausschließlich mit der BC-Methode hergestellt, in den USA wird die Plättchenreiches-Plasma-(PRP) Methode bevorzugt [8]. Im weiteren Verlauf konzentriert sich diese Stellungnahme auf PTK, die mit der BC-Methode hergestellt wurden, da sich die PTK in mehreren Aspekten in Abhängigkeit von der Herstellungsmethode unterscheiden. Dies ist bei der Betrachtung international veröffentlichter Daten zu TK zu beachten.

Um eine therapeutische Einheit mit den erforderlichen aktuellen Spezifikationen zu erhalten, werden in Deutschland in aller Regel die Thrombozyten von vier Spenden für ein nicht-pathogeninaktiviertes PTK gepoolt [6]. Nur eine Einrichtung hat aktuell eine Zulassung für PTK, hergestellt aus 5 Vollblutspenden. Kalkuliert aus den Daten gemäß $\$ 21$ Transfusionsgesetz (TFG) entspricht das einem Anteil von maximal
$1,25 \%$ aller 2013 in Deutschland hergestellten PTK. International wird ein Pooling der $\mathrm{BC}$ aus 4 bis 6 Vollblutspenden berichtet [7].

\subsection{Vom Vollblut zum PTK: Zeitabläufe und Lagerungsbedingungen}

Die Herstellung von PTK muss auch im Gesamtkontext der Prozessierung von Vollblutspenden betrachtet werden. Daher werden in den folgenden Abschnitten der Einfluss von Dauer und Bedingungen der Vollblutlagerung auf die Qualität der hergestellten Blutprodukte bewertet.

Da Thrombozyten bei Temperaturen unterhalb der Raumtemperatur aktiviert werden und kälteaktivierte Thrombozyten in vivo rasch sequestriert werden [9-11], müssen Vollblutspenden, aus welchen PTK hergestellt werden sollen, bis zur Separation der Komponenten bei $+22^{\circ} \mathrm{C}$ gelagert werden. Die Richtlinien-Vorgaben für das maximale Intervall zwischen Vollblutspende und Verarbeitung variieren von $8 \mathrm{~h}$ [12] bis $24 \mathrm{~h}$ nach Vollblutspende [13]. Die Herstellungsverfahren in Deutschland variieren von einer Separation zu einem früheren Zeitpunkt nach Vollblutspende bis zu Separation und Pooling am Folgetag nach der Spende, liegen jedoch schon aufgrund der Vorgaben zum maximale Zeitintervall bis zum Einfrieren von Gefrorenem Frischplasma (GFP) deutlich unter $24 \mathrm{~h}$ [5]. Es ist zu berücksichtigen, dass die Mehrzahl der Vollblutspenden in Deutschland durch mobile Teams auf externen Entnahmeterminen erfolgt, und sich allein durch den Transport der Vollblutspenden in die verarbeitenden Institute häufig ein relevantes Intervall ergibt.

Die aktuelle Datenlage bietet keinen Anhalt dafür, dass eine Raumtemperaturlagerung der Vollblutspenden bis zur PTK-Herstellung einen nachteiligen Einfluss auf die PTK-Qualität hat, solange das Intervall geringer als $24 \mathrm{~h}$ ist [1421]. Einige Studien sprechen sogar dafür, dass eine Übernachtlagerung mit zeitverzögerter Präparation die Qualität der PTK im Hinblick auf Thrombozytengehalt und Funktion verbessert und das
Restrisiko bakterieller Kontamination verringert [22-27].

\subsection{PTK aus Vollblut: Auswirkungen auf die anderen Blutkomponenten aus Vollblut}

Vor dem Hintergrund der Lagerungsbedingungen und zeitlichen Abläufe bei der PTK-Herstellung stellt sich die Frage, ob durch die Herstellung von PTK aus der Vollblutspende nachteilige Auswirkungen auf Erythrozytenkonzentrate (EK) und Plasma resultieren.

\subsubsection{2,3-Biphosphoglycerat (2,3-BPG)-Gehalt in Erythrozyten}

2,3-Biphosphoglycerat ist ein Molekül, das für die Sauerstoffabgabe aus Erythrozyten an das Gewebe wichtig ist. Ein geringer 2,3-BPG-Gehalt führt zu einer schlechteren Abgabe des Sauerstoffes aus den Erythrozyten. Durch eine Lagerung bei Raumtemperatur wird das in der Spende vorhandene 2,3-BPG schnell abgebaut. Dieser Abbau wird durch rasche Kühlung der Vollblutspenden verlangsamt. Allerdings liegt der 2,3-BPG-Gehalt der Erythrozyten nach 21 Tagen Lagerung unabhängig von der initialen Lagerungstemperatur unterhalb der Nachweisgrenze [28]. Der 2,3-BPG-Gehalt in Erythrozyten kehrt jedoch nach Transfusion in vivo rasch zu annähernd normalen Werten zurück [29-32]. Die Untersuchung von Wilsher et al. kommt zum Ergebnis, dass aus Vollblutspenden, welche ohne Einsatz von Kühlplatten $24 \mathrm{~h}$ lang bei Raumtemperatur gelagert werden, EK und GFP angemessener Qualität hergestellt werden können [28].

\subsubsection{Hb-Gehalt der EK}

Die unterschiedlichen Herstellungsverfahren beeinflussen den $\mathrm{Hb}$-Gehalt der EK. Dieser ist ein wichtiger Qualitätsparameter und er beeinflusst den Hb-Anstieg nach Transfusion [33]. Der Hb-Gehalt der EK ist abhängig vom Herstellungsverfahren. Hier ist insbesondere die vorgeschriebene Leukozytendepletion der zellulären Blutprodukte wichtig. Um die für die EK erforderliche Leukozytendepletion zu erreichen, werden entweder Vollblutspenden ohne vorherige Separation ge- 
filtert (Vollblutfiltration), oder das nach einer ersten Zentrifugation des Vollbluts und anschließender Komponententrennung gewonnene EK (EK-Inline-Filtration). Die Art der Leukozytendepletion bestimmt auch, ob aus der Vollblutspende noch TK hergestellt werden können.

Nach einer Vollblutfiltration können aus dieser Spende keine Thrombozytenkonzentrate mehr hergestellt werden, da bei der Filtration des noch nicht separierten Vollblutes auch die Thrombozyten entfernt werden. Bei Vollblutfiltration sind die Erythrozytenverluste geringer, entsprechend ist der $\mathrm{Hb}$-Gehalt des Endproduktes um ca. $10 \%$ höher [34]. Allerdings wird bei diesem Vorgehen weniger Plasma gewonnen.

Bei der EK-Filtration wird zunächst die Vollblutspende durch Zentrifugation aufgetrennt. Hierbei entsteht ein EK, das anschließend leukozytendepletiert wird. Zusätzlich entstehen ein Plasma und ein BC. Letzterer kann für die Herstellung von PTK genutzt werden. Bei der EK-Filtration ist der Erythrozytenverlust gröBer als bei der Vollblutfiltration. Dieser Erythrozytenverlust ist jedoch unabhängig davon, ob aus dem gewonnenen $\mathrm{BC}$ noch ein TK hergestellt wird oder nicht. Bei angepassten Einstellungen des Separators ist der $\mathrm{Hb}$-Gehalt der EK mit und ohne PTK-Herstellung bei EK-Inline-Filtration nicht signifikant unterschiedlich [35]. Bei der EK-Filtration wird ca. $10 \%$ mehr Plasma gewonnen als bei der Vollblutfiltration.

Die Vorgaben der HämotherapieRichtlinien [5], welche einen Mindestgehalt von $40 \mathrm{~g}$ Hämoglobin pro EK verlangen, werden unabhängig von der Wahl der Herstellungslinie (Vollblutfiltration bzw. EK-Inline-Filtration) eingehalten.

Insgesamt ist die Optimierung der Herstellung aller Blutkomponenten in einer „Dreilinienstrategie“ (EK, Plasma und PTK) oder einer „Zweilinien“-Strategie (EK und Plasma) Gegenstand aktueller Kontroversen [28, 35-37]. Einige Autoren vertreten die Auffassung, dass der geringere $\mathrm{Hb}$-Gehalt der EK nach EK-Filtration zu einem höheren EK-Transfusionsbedarf führt $[37,38]$. Es bedarf weiterer Studien, v. a. im Hinblick auf klinische Relevanz der in den Studien untersuchten Parameter. Eine Betrachtung der unterschiedlichen „Dreilinien“- bzw. „Zweilinien“-Herstellungsstrategie muss stets den Bedarf an allen Komponenten einschließen. Weiterhin sind die Vor- und Nachteile dieser Herstellungswege auch gegenüber den Herstellungswegen durch Apheresetechnologien abzuwägen. Neue Entwicklungen („platelet-sparing“Leukozytenfiltration im Vollblut) ermöglichen, eine Vollblutfiltration mit einer PTKHerstellung zu kombinieren $[39,40]$. Im Vergleich gleichartiger Herstellungslinien (EK-Inline-Filtration mit bzw. ohne PTK-Herstellung) ergibt sich kein Unterschied im Hb-Gehalt der resultierenden EK. Grundsätzlich bedürfen alle Herstellungslinien einer sehr sorgfältigen Optimierung der Arbeitsschritte für eine optimale Verwendung der Vollblutspende bei gleichzeitig hoher Qualität der Produkte.

\subsection{Herstellung von ATK}

ATK werden vom Einzelspender mittels maschineller Thrombozytapherese gewonnen. Dabei handelt es sich um ein Spendeverfahren mit extrakorporalem Kreislauf. Grundsätzlich wird bei der Thrombozytapherese das Blut des Spenders durch eine Armvene entnommen, das unter Zusatz eines blutgerinnungshemmenden Mittels in einen Zellseparator fließt. In diesem werden durch kontinuierliche Zentrifugation die Blutbestandteile aufgrund ihrer physikalischen Eigenschaften aufgetrennt. Die Zellseparatoren sind bei der ATK-Spende derart eingestellt, dass sie die Fraktion der Thrombozyten sammeln, während die übrigen für die Spende nicht benötigten Blutbestandteile kontinuierlich oder intermittierend über dieselbe oder eine andere Armvene in den Körper des Spenders zurückfließen (Einarm- bzw. Zweiarmtechnik).

Bereits in der zweiten Hälfte des vergangenen Jahrhunderts wurden Maschinen entwickelt, die in der Lage waren, weitgehend selektiv bestimmte Blutbestandteile - hier Thrombozyten - zu gewinnen. Seit den 1970er Jahren gelang dies auch unter Verwendung von Einmalentnahmesets. Im Regelfall können mit den heutigen Systemen von einem Blutspender innerhalb eines Zeitraums von 40 bis 90 min mittels Thrombozytapherese bei einer Sitzung über $8 \times 10^{11}$ Thrombozyten gesammelt werden $[41,42]$ und bis zu drei oder in Ausnahmefällen spenderabhängig sogar vier therapeutische Einheiten mit einer Thrombozytenzahl von 2,5-3 $\times 10^{11}$ hergestellt werden [41-46]. Diese enthalten weniger als $1 \times 10^{6}$ Leukozyten.

\subsection{Suspensionsmedium für die Thrombozyten: Plasma oder additive Lösung}

Als Suspensionsmedium für Thrombozyten kann entweder ausschließlich Plasma oder Plasma in Kombination mit additiven Lösungen eingesetzt werden. Durch additive Lösungen kann der Plasmaanteil auf ca. $30 \%$ oder darunter reduziert werden. Die Eigenschaften der additiven Lösung beeinflussen Qualität, Metabolismus, Wiederfindungsrate und Funktion der Thrombozyten [47-49]. In PTK in additiver Lösung beträgt die noch im PTK enthaltene Restplasmamenge jedes einzelnen Spenders etwa 20-25 ml. Die additiven Lösungen wurden in den letzten Jahren kontinuierlich weiterentwickelt. Biologischer Zweck der additiven Lösungen ist, ein Substrat für den Energiestoffwechsel zur Verfügung zu stellen, durch Pufferkapazität den für Thrombozytenlagerung optimalen $\mathrm{pH}$-Wert zu stabilisieren, Thrombozytenlagerungsschäden zu vermindern und somit die Thrombozytenfunktion möglichst gut zu bewahren [47, $48,50]$. Da verschiedene additive Lösungen im Einsatz sind, ergibt sich auch dadurch ein Unterschied zwischen den TK. In Deutschland sind vor allem nicht-glucosehaltige additive Lösungen im Einsatz.

Der teilweise Ersatz von Plasma durch additive Lösung spart Plasma für die Herstellung von Plasmakomponenten ein, ermöglicht die Anwendung von Pathogeninaktivierungstechnologien und vermindert akute, nicht-hämolytische Transfusionsreaktionen und möglicherweise auch transfusionsassoziierte Lungeninsuffizienz (TRALI) und Hämolyse nach AB0minor-inkompatiblen Transfusionen [5052]. Es wurde nachgewiesen, dass additive Lösung die Bildung von Biofilmen durch Bakterien in TK reduziert und den Nachweis der bakteriellen Kontamination in TK erleichtert [53, 54]. Die Häufigkeit 
akuter unerwünschter Transfusionsreaktionen nach TK-Gabe konnte durch Leukozytendepletion und Plasmareduktion weiter reduziert werden [55-58], wobei beide Methoden vergleichbar effektiv sind [57, 59-62].

Studien, welche Thrombozytenanstieg und klinische Endpunkte, z. B. Blutungskomplikationen, zwischen TK in $100 \%$ Plasma und TK in additiver Lösung verglichen, berichteten auf den ersten Blick widersprüchliche Daten. Dies lag jedoch an den unterschiedlichen additiven Lösungen. Mit neu entwickelten additiven Lösungen (der so genannten dritten Generation) bzw. glucosehaltigen additiven Lösungen werden bessere Ergebnisse berichtet. Ein randomisierter Vergleich von Thrombozytenkonzentraten, welche entweder in einer nicht-glucosehaltigen additiven Lösung oder Plasma gelagert wurden, zeigte einen geringeren korrigierten Thrombozytenanstieg (CCI) nach einer bzw. 24 h [60]. Dies bestätigte Daten einer früheren Studie [63]. Allerdings waren trotz der niedrigeren CCI-Werte keine signifikanten Unterschiede bei Blutungskomplikationen, Transfusionsintervallen oder Gesamtbedarf an TKoder Erythrozytentransfusionen festzustellen [60]. Patientenabhängige Variablen waren für unzureichenden Thrombozytenanstieg nach Transfusion bedeutsamer als die Eigenschaften der TK [60].

Es ist möglich, auch ATK plasmareduziert in additiver Lösung herzustellen [64-69]. Dies wird auch zunehmend durchgeführt. Untersuchungen von in vitro Qualitäts- und Funktionsparametern zeigen überwiegend gute Werte für die plasmareduzierten ATK [49, 64, 6668]. Allerdings gibt es auch eine Studie, welche überlegene Funktionsparameter für ATK in $100 \%$ Plasma zeigt [68]. Bisher ist es jedoch unklar, ob in vitro nachweisbare Unterschiede zwischen ATK in $100 \%$ Plasma und ATK in additiver Lösung auch für die klinische Wirksamkeit der beiden Produktvarianten bedeutsam sind [65].

Aktuell ist zu berücksichtigen, dass viele Studien mit PTK auf Präparaten in additiver Lösung basieren, während die ATK mehrheitlich in $100 \%$ Plasma resuspendiert sind. Entsprechend stellt ein Vergleich zwischen ATK und PTK vielfach einen kombinierten Vergleich der unterschiedlichen Methoden für die Gewinnung der TK sowie der unterschiedlichen Medien für die Lagerung (Plasma vs. additive Lösungen) dar. Daten aus den Angaben aus der Zulassung beim Paul-Ehrlich-Institut zeigen, dass 2014 etwa 79\% der PTK in Additivlösung hergestellt wurden und $16 \%$ der ATK.

\section{Therapeutische Aspekte}

\subsection{Indikation}

Die Gabe von Thrombozytenkonzentraten ist indiziert zur Behandlung einer Blutungsneigung, bedingt durch eine schwere Thrombozytopenie infolge thrombozytärer Bildungsstörungen, im Notfall auch bei Umsatzstörungen, jedoch nicht bei einer niedrigen Thrombozytenzahl allein. Damit durch Transfusion von Thrombozyten eine Besserung der thrombozytär bedingten Blutungsneigung zu erwarten ist, sollte vor der Behandlung zunächst deren Ursache abgeklärt werden (PaulEhrlich-Institut: Muster Gebrauchs- und Fachinformation für Thrombozytenkonzentrate, verfügbar unter [70]).

Blutungen werden nach verschiedenen Schweregraden eingeteilt. Hierbei gibt es verschiedene Klassifikationssysteme [71]. In der Klassifikation, die von der WHO vorgeschlagen wird, versteht man unter einer Blutung Grad 1 eine milde Blutung, z. B. vereinzelte Petechien oder kurze Episoden von Nasenbluten oder eine Mikrohämaturie. Zu den Grad 2 Blutungen werden alle geringgradigen Blutungen gezählt, die keiner Erythrozytentransfusion bedürfen. Bei Grad 3 Blutungen handelt es sich um Blutungen, die grundsätzlich zusätzliche Transfusionen erforderlich machen. Als Grad 4 Blutung bezeichnet man Blutungen im zentralen Nervensystem, Retinablutungen mit Visusverlust, Blutungen, die zum hämorrhagischen Schock führen und tödliche Blutungen.

Die Einteilung nach Blutungsgraden wird in verschiedenen Studien nicht einheitlich gehandhabt und dies muss bei der vergleichenden Interpretation von Ergebnissen von Interventionen beachtetet werden [71, 72]. Es gibt daher derzeit internationale Bemühungen, die unterschiedlichen Blutungsgrade in erster Li- nie nach ihrer klinischen Relevanz für den Patienten zusammenzufassen [73].

Das Risiko von klinisch relevanten Blutungen ist, wie zahlreiche klinische Studien belegen konnten, nicht ausschließlich von der Zahl der Thrombozyten im peripheren Blut abhängig. Insbesondere ist es von krankheits- und therapiebedingten Faktoren des Patienten geprägt. Die aktuelle Situation des Patienten ist daher oft wichtiger als die Messung des morgendlichen Thrombozytenwerts im Blut $[74,75]$.

Transfusionen von TK sollten grundsätzlich auf das notwendige Maß beschränkt werden, da sie mehrere und selten auch tödliche Nebenwirkungen haben [76-80]. In den letzten Jahren sind zwei Maßnahmen geprüft worden mit dem Ziel, die Anzahl der Thrombozytentransfusionen bei Patienten mit hypoproliferativer Thrombozytopenie zu verringern und um damit letztendlich das Risiko von Infektionsübertragungen oder von immunologischen Komplikationen zu reduzieren. Diese Maßnahmen sind

1. die therapeutische Gabe von Thrombozyten im Vergleich zu prophylaktischen Thrombozytentransfusionen und

2. die Gabe niedrig-dosierter im Vergleich zu Standard-dosierter Thrombozytenkonzentrate.

\subsection{Prophylaktische versus therapeutische Transfusionsstrategie}

Die Querschnitts-Leitlinien der Bundesärztekammer von 2008 unterscheiden zwischen akuter und chronischer Thrombozytopenie [81]. Bei akuter Thrombozytopenie aufgrund einer Thrombozytenbildungsstörung wird bei klinisch stabilen Patienten eine prophylaktische Gabe von TK ab einem Grenzwert 10.000/ $\mu \mathrm{L}$ empfohlen. Bei Vorliegen von Komplikationen wie Fieber $>38^{\circ} \mathrm{C}$, petechialer Blutungen, Infektionen, GVHD, Leukozytose, plasmatischer Gerinnungsstörung, steilem Thrombozytenabfall und vorbestehenden Nekrosebereichen sollte bereits ab einem Grenzwert von 20.000/ $\mu \mathrm{L}$ transfundiert werden. Im Falle von manifesten Blutungen soll therapeutisch transfundiert werden, um zusammen mit an- 
deren blutstillenden Maßnahmen die Blutung zu stoppen. Diese Empfehlungen decken sich mit den international üblichen Standards [82].

Bei chronischer Thrombozytopenie wird im Sinne einer therapeutischen Strategie bei ambulanten Patienten, wenn sie kein Fieber über $38^{\circ}$ haben, ein zurückhaltenderes Vorgehen vorgeschlagen: Bei wöchentlicher Blutbildkontrolle sollen TK erst transfundiert werden, wenn die Thrombozytenwerte unter 5000/ $\mu \mathrm{l}$ liegen oder bei manifester Blutung (WHO Grad $3+4)$ und vor chirurgischen Eingriffen [83]. Bei Patienten mit erhöhtem Thrombozytenumsatz (z. B. Immunthrombozytopenie, Thrombozytisch-thrombozytopenische Purpura, disseminierte intravasale Gerinnung) soll erst beim Auftreten bedrohlicher Blutungen transfundiert werden.

Bei invasiven Prozeduren (außer bei Knochenmarkpunktion) sollen die Thrombozyten auf jeden Fall mindestens über 20.000/ $\mu$ l gehalten werden, ggf. durch die Transfusion von TK direkt vor dem Eingriff. So reichen z. B. für die Anlage eines zentralvenösen Katheters Werte zwischen 20.000-30.000/ $\mu$ l, während für eine Leberpunktion und Spinalanästhesie Werte $>50.000 / \mu$ l gefordert werden. Bei neurochirurgischen Eingriffen sollen die Thrombozytenwerte $>80.000 / \mu \mathrm{l}$ sein.

Über die Leitlinienempfehlungen hinaus gibt es auf Basis neuerer Untersuchungen grundsätzlich eine Diskussion darüber, ob schwere Blutungen eher durch eine regelmäßige prophylaktische Transfusion von TK bei Unterschreiten eines bestimmten Grenzwerts oder eher durch die gezielte therapeutische Transfusion bei ersten Zeichen einer geringen Blutung vermieden werden können [74, 75, 84-90]. Zwei neuere Studien bei hämatologischen Patienten nach einer intensiven Chemotherapie haben in der Routine randomisiert eine prophylaktische mit einer therapeutischen Strategie verglichen $[89,91]$. Zwei weitere Studien mit historischem Vergleich [92-94] haben ebenfalls die Durchführbarkeit der therapeutischen Strategie untersucht. In diesen Studien konnte gezeigt werden, dass bei hämatologischen Patienten mit niedrigem Blutungsrisiko (nach autologer Stammzelltransplantation) eine the- rapeutische Strategie grundsätzlich möglich ist und damit die Transfusion von TK um 33-41\% für diese Patienten reduziert werden kann.

Bei Patienten mit höherem Blutungsrisiko (z. B. bei neu diagnostizierten akuten Leukämien) sollte in jedem Fall, wie in den Leitlinien vorgesehen, in der Routine unter Sicherheitsaspekten eine prophylaktische Strategie verfolgt werden. Eine vordefinierte Subgruppenanalyse der so genannten TOPPS-Studie zeigte bei Patienten unter Chemotherapie oder nach allogener Stammzelltransplantation eine stärkere Reduktion der Blutungsereignisse durch prophylaktische Transfusionsstrategie als bei Patienten nach autologer Stammzelltransplantation [90]. In diesen Studien wurden fast ausschließlich ATK verwendet $[83,87,95]$.

Eine Aktualisierung des systematischen Reviews der Cochrane Gesellschaft [94] wird weitere Ergebnisse zur Frage der Effektivität und Sicherheit (insbesondere mit Blick auf schwere intrakranielle bzw. intrazerebrale Blutungen) von therapeutischen vs. prophylaktischen Thrombozytentransfusionen bei Patienten mit malignen hämatologischen Erkrankungen anhand aktueller Studien aufzeigen.

\subsection{Thrombozytendosis pro TK}

In Deutschland wird in der Regel entsprechend den Anforderungen der Querschnitts-Leitlinien pro TK eine Dosis von $2-4 \times 10^{11}$ Thrombozyten gefordert. Bisher wurde in Deutschland zumeist ein durchschnittlicher Thrombozyten-Gehalt von $3 \times 10^{11}$ Thrombozyten je hergestelltem ATK bzw. PTK angestrebt. Zur Frage der richtigen Dosierung in der Thrombozytentransfusion sind in den letzten Jahren wichtige Studien publiziert worden. Die meiste Beachtung gefunden hat hierbei der so genannte PLADO-Trial [96]. Hierbei handelte es sich um eine multizentrische klinische Studie an $1272 \mathrm{~Pa}-$ tienten in den USA. Diese Patienten erhielten wegen hyporegenerativer Thrombozytopenie prophylaktisch ATK oder PTK, wobei der auch in Deutschland übliche Standard-Transfusionstrigger von $10.000 / \mu \mathrm{L}$ verwendet wurde. Die Patienten wurden in drei Vergleichsgruppen randomisiert und erhielten je Transfu- sionsereignis 1,1 oder 2,2 oder $4,4 \times 10^{11}$ Thrombozyten pro $\mathrm{m}^{2}$ Körperoberfläche. Die Frequenz von Blutungsereignissen aller WHO-Schweregrade war in den drei Behandlungsgruppen gleich. Die mediane Körperoberfläche der in dieser Studie behandelten Patienten war in allen drei Behandlungsgruppen jeweils $1,9 \mathrm{~m}^{2}$. Diese Körperoberfläche entspricht auch der durchschnittlichen Körperoberfläche in Deutschland lebender Patienten. Im Median erhielten die Patienten in der low-dose-Gruppe absolut $1,85 \times 10^{11}$ Thrombozyten (Interquartile 1,64 bis $1,99 \times 10^{11}$. Damit konnte eine signifikante Reduktion der transfundierten Thrombozyten um ca. $20-25 \%$ zur mittleren/StandardDosis-Gruppe erreicht werden. Bezogen auf den durchschnittlichen deutschen $\mathrm{Pa}$ tienten liegt der bisher gebräuchliche Gehalt an Thrombozyten/Präparat bei ca. $3 \times 10^{11}$ und somit genau in der Mitte zwischen der niedrigen und der mittleren Dosis im PLADO-Trial.

Überträgt man die Studienergebnisse des PLADO-Trials auf die Transfusionspraxis in Deutschland würde eine Anforderung $\mathrm{z}$. B. von nur noch ca. $2 \times 10^{11}$ Thrombozyten pro TK zu einer nennenswerten Reduktion der absolut transfundierten Thrombozyten führen. Für die Herstellung eines PTK würden nicht mehr vier sondern nur noch drei Buffycoats benötigt und aus einer Apherese könnten nicht nur in der Regel ein Doppel- sondern ein Dreifachpräparat gewonnen werden. Sollte klinisch ein erhöhter Transfusionsbedarf an Thrombozyten notwendig werden z. B. wegen Blutung, so könnte auf zwei oder mehrere TK zurückgegriffen werden. Eine solche Änderung der Anforderung an den Thrombozytengehalt eines TK würde in der prophylaktischen Routine (und dies sind in der Praxis 80-90\% der Transfusionen) zu einer klinisch relevanten $\mathrm{Re}$ duktion des Thrombozytenbedarfs führen. Es ist jedoch zu berücksichtigen, dass in der US-amerikanischen Studie in der low-dose Gruppe eine Steigerung der Transfusionsepisoden um $33 \%$ im Vergleich zur Standardgruppe in Kauf genommen werden musste, was einer vermehrten Spenderexposition entsprach. In Deutschland ist die verwendete Standarddosis pro TK niedriger als die in den 
USA und hier werden PTK aus buffy coat verwendet, die den in den USA verwendeten PTK aus plättchenreichem Plasma qualitativ überlegen sind. Weiterhin werden TK im Transfusionsalltag nicht nach Körperoberfläche dosiert, sondern erwachsene Patienten erhalten Standardpräparate mit mindestens $2 \times 10^{11}$ und durchschnittlich $3 \times 10^{11}$ Thrombozyten. Ob die Ergebnisse des PLADO-Trials auf Deutschland insbesondere unter Berücksichtigung von Blutungsrisiken übertragen werden könnten, bedarf daher weiterer Untersuchungen.

\subsection{Management des Therapie- refraktären Patienten}

Die Refraktärität gegenüber Thrombozytentransfusionen ist gekennzeichnet durch einen fehlenden Anstieg der Thrombozytenwerte trotz wiederholter Transfusion von AB0-kompatiblen, frischen TK. Hierfür gibt es sowohl nichtimmunologische Ursachen (z. B. die Splenomegalie mit vermehrtem Pooling von Thrombozyten in der Milz, Fieber, Blutungen, große Wundflächen sowie Sepsis) als auch immunologische Ursachen. Nicht-immunologische Ursachen sind mit ca. $70 \%$ deutlich häufiger als immunologische [97]. Liegt eine nicht-immunologische Ursache der Refraktärität vor, so lässt sich durch eine Transfusion von mehreren TK nacheinander ein Thrombozytenanstieg erreichen.

Die Immunisierung von Patienten in diesem Zusammenhang bedeutet, dass Patienten Antikörper gegen bestimmte Antigene, die sich auf der Oberfläche von Leuko- oder Thrombozyten befinden, gebildet haben (HLA- oder HPA-Antikörper). Diese Antikörper können dazu führen, dass transfundierte Thrombozyten, die das entsprechende Antigen besitzen, durch den Antikörper des Patienten beschleunigt abgebaut und zerstört werden. Damit haben die transfundierten Thrombozyten keine adäquate Wirksamkeit und der Patient hat ein deutlich höheres Blutungsrisiko. Bei solchen Patienten treten signifikant häufiger Blutungen aller Schweregrade auf, bis hin zu akut lebensgefährdenden Hirnblutungen. Das mediane Überleben hämatologischer Patienten ist bei Thrombozytenrefraktärität na- hezu halbiert. Die Frage der raschen Verfügbarkeit geeigneter typisierter TK ist daher für diese Patienten von immenser Bedeutung.

Im Falle der Thrombozytenrefraktärität von immunisierten Patienten besteht die Indikation zur Gabe von TK, die entsprechend dem HLA- oder HPA-AntigenMuster von Spender und Empfänger speziell ausgewählt werden. Zusätzliche Voraussetzung ist, dass entweder die HLAund/oder HPA-Merkmale des Empfängers bestimmt wurden oder dass die genaue Spezifität der Antikörper des Patienten geklärt wurde, damit eine Auswahl der geeigneten Spender erfolgen kann (Positiv- bzw. Negativselektion geeigneter Spender). Da in der Regel nur regelmäßige Apherese-Spender HLA- und/oder HPA-typisiert werden, und die Herstellung von typisierten PTK nicht umsetzbar ist, kommen zur Gabe patientenbezogener Thrombozytenkonzentrate nur ATK speziell ausgewählter Spender in Frage.

Um solche ATK gewinnen zu können, müssen ausreichend typisierte ATKSpender zur Verfügung stehen. Gleichzeitig müssen die Wege und Zeitabläufe kurz sein (kliniknahe Versorgung). Daher sind zur sicheren und gesicherten Versorgung solcher Patienten mit immunologisch bedingter Thrombozytenrefraktärität ausreichend viele Apheresezentren erforderlich, die über einen hinreichend typisierten aktiven Spenderstamm und genügend Erfahrung in der Technik der Thrombozytapherese verfügen.

\subsection{Anwendung von TK in Deutschland}

Die Erfassung des Verbrauchs an TK in den Einrichtungen der Krankenversorgung erfolgt ohne Zuordnung nach der Indikation, so dass die an das Paul-Ehrlich-Institut (PEI) nach $\$ 21$ TFG gemeldeten Daten keine Auskunft darüber geben, für welche Indikationen die TK anteilig angewendet werden. Daher wurden aus den Daten nach $\$ 21$ TFG Einrichtungen der Krankenversorgung ermittelt, die 2011 einen Verbrauch von mehr als 2000 TK gemeldet hatten. Diese 52 Einrichtungen wurden gebeten, dem PEI den Verbrauch nach Indikation für die Jahre 2011 bis 2012 mitzuteilen. Insbesondere wur- de der Anteil an TK erfragt, der therapeutisch wegen eines Blut- bzw. Thrombozyten-Verlusts (Notfallpatienten, Chirurgie ohne Organtransplantation) eingesetzt wurde sowie der Anteil für Patienten mit Thrombozyten-Bildungsstörungen (hämatologisch/onkologische Indikationen). Danach ließe sich einschätzen, wie viele Thrombozytenkonzentrate in den Einrichtungen der Krankenversorgung als Basis vorzuhalten wären.

Die Auswertung der Rückläufe ergab, dass in den 2 Jahren etwa $75 \%$ aller TK in den hämatologisch-onkologischen Abteilungen einschließlich der Pädiatrie transfundiert wurden, also vermutlich vor allem prophylaktisch eingesetzt wurden. Vergleichbare Daten wurden aus einer Stichprobenuntersuchung an einem Klinikum der Maximalversorgung gewonnen.

Nach einer aktuellen internationalen Übersicht [98] nehmen die TK-Transfusionen in allen Ländern kontinuierlich zu. Dies ist vor allem durch steigende Patientenzahlen in der Hämatologie/Onkologie bedingt, wo mit immer besseren Behandlungsmethoden auch immer ältere Patienten behandelt werden können. In dieser Arbeit wird auch darauf hingewiesen, dass durch das nicht Leitlinien-gerechte Transfusionsverhalten unnötig viele TK verabreicht werden (um ca. $30 \%$ mehr). Dies deckt sich mit einer Stichprobenerhebung am Klinikum Großhadern in München (persönliche Mitteilung H. Ostermann).

\section{Wirksamkeit von TK und Wirksamkeitsunterschiede}

\subsection{In Vitro Funktionalität}

Thrombozytenpräparate können mit verschiedenen Verfahren hinsichtlich ihrer in vitro Funktionalität untersucht werden. Diese Untersuchungen sind regelmäßiger Bestandteil von Validierungsuntersuchungen im Rahmen der Produktzulassung. Es muss demonstriert werden, dass die gewonnenen Präparate in den durchgeführten Untersuchungen eine hinreichende Funktionalität vermuten lassen.

In der Regel nutzen die Antragsteller für den Nachweis der Funktionalität ihrer Präparate folgende Tests: Die Thrombozyten-Aggregation wird als Maß für die 
Aktivierbarkeit der Thrombozyten eingesetzt, die hypotone Schockresistenz (HSR) als Maß für die Integrität von Membran und Energiestoffwechsel oder die P-Selektin-Expression (CD62P) auf der Plättchenoberfläche im Ruhezustand als Maß für die Voraktivierung bzw. die P-Selektin-Expression nach Stimulierung mit Agonisten als Maß für die Aktivierbarkeit der Thrombozyten. Es handelt sich um Methoden, von denen gezeigt werden konnte, dass sie in gesunden Probanden mit der in vivo Wiederfindungs- bzw. Überlebensrate der Thrombozyten korrelieren [99-103].

Die Messbedingungen müssen für die Qualitätskontrolle von TK adaptiert werden, d. h., Kontrollen, Konzentration der verwendete Agonisten etc. sind neu zu definieren, da sich die Matrizes (Additivlösungen, Plasma, Zitrat) der TK erheblich von klinischem Untersuchungsmaterial aus frisch entnommenem Zitrat-Blut unterscheiden.

Die so erhaltenen in vitro Daten erlauben eine Aussage über die gleichmäßige, angemessene Qualität der Thrombozytenpräparate nach dem heutigen Stand der medizinischen Wissenschaft und Technik. Sie lassen entsprechend der in gesunden Probanden ermittelten in vivo Überlebensraten. Sie lassen eine angemessene Funktionalität der Präparate im Patienten vermuten, auch wenn der Thrombozytenanstieg nach Transfusion zusätzlich entscheidend von der jeweiligen klinischen Situation der Patienten bestimmt wird (s. u.).

\subsection{Thrombozytenanstieg und Blutungskomplikationen nach Transfusion von TK}

Die in-vivo Wirkung der Thrombozytenkonzentrate kann durch verschiedene Variablen beeinflusst werden (transfundierte Thrombozytenzahl, additive Lösung, Herstellungsmethode, AB0-Kompatibilität, Lagerungsschaden, Situation des Empfängers).

Um den Thrombozytenanstieg durch Transfusion zu messen, wird der CCI (corrected count increment) verwendet. Dieser bezieht den gemessenen Anstieg der Thrombozytenzahlen unter Berück- sichtigung der Transfusionsdosis auf die Körperoberfläche.

Der CCI ist ein häufig verwendeter Surrogat-Parameter zur Quantifizierung des in vivo Transfusionseffektes. Mehrere Studien verglichen den CCI nach Transfusion von ATK und PTK [57, 104-110]. Diese zeigten keinen signifikanten Unterschied in den CCI-Werten nach BC-PTK und ATK, auch wenn sich die Präparate in weiteren Parametern (Leukozytendepletion, Suspensionslösung) unterschieden [57, 104-112]. Auch das Intervall bis zur nächsten Transfusion unterschied sich nicht [111]. Eine Studie mit kleiner Fallzahl bei AML-Patienten nach Stammzelltransplantation zeigte höhere Thrombozytenzahlen nach ATK-Transfusion, aber keinen signifikanten Unterschied der Blutungskomplikationen [109].

Eine Sekundäranalyse der oben aufgeführten PLADO-Studie zeigte ein höheres Thrombozyteninkrement und korrigiertes Thrombozyteninkrement nach Transfusion von ATK, AB0-identischen TK und TK mit Lagerungsdauer von 3 Tagen vs. 4-5 Tagen [113]. Die in dieser Studie eingesetzten PTK wurden mit der PRPMethode hergestellt. Modellierungen zeigten, dass die Herstellungsverfahren (ATK oder PRP-PTK), keinen Einfluss auf die Zeit bis zum Eintreten der ersten Blutung mit einem WHO-Grad 2 oder höher hatten. Gleiches zeigte sich auch für Blutungen mit WHO Grad $>3$ wobei die Aussagekraft dieser Analyse aufgrund der geringen Inzidenz der WHO Grad $\geq 3$ Blutungen gering war [113].

In dieser Studie konnte somit trotz Unterschieden der CCI-Werte keine Assoziation zwischen verschiedenen Charakteristika der Thrombozytentransfusion (Dosis, AB0-Konstellation, Lagerungsdauer, Herstellungsverfahren) und der Häufigkeit von Blutungen nachgewiesen werden. Die Unterschiede der CCI-Werte waren gering und wahrscheinlich ohne klinische Relevanz. Die medianen CCI-Werte lagen jeweils über der Schwelle von 50007500 , welche als untere Grenze für einen inadäquaten Thrombozytenanstieg angesehen wird [113].

Die Studie „Trial to Reduce Alloimmunization to Platelets" (TRAP) zeigte, dass der CCI signifikant mit AB0-Kompatibilität und geringerer Lagerungsdau- er (bis $48 \mathrm{~h}$ ), aber nicht mit dem Herstellungsverfahren (PRP-PTK, ATK) assoziiert war [114]. Geringere Lagerungsdauer (bis $48 \mathrm{~h}$ ) und die transfundierte Thrombozytenzahl waren auch mit signifikant längerer Zeit bis zur nächsten Transfusion assoziiert. Dagegen hatten das Herstellungsverfahren und die AB0-Kompatibilität keinen signifikanten Einfluss auf die Zeit bis zur nächsten Transfusion [114]. Der negative Zusammenhang zwischen CCI-Werten und der Lagerungsdauer wurde auch in anderen Studien berichtet $[97,115]$ und ist unabhängig vom Herstellungsverfahren $[105,108,115]$.

In der Bewertung der Einflussfaktoren müssen neben den Präparate-abhängigen Faktoren insbesondere auch Patientencharakteristika berücksichtigt werden, welche mit schlechterem Thrombozytenanstieg nach Transfusion und kürzeren Intervallen bis zur nächsten Transfusion assoziiert sind (Schwangerschaften, Splenomegalie, Fieber, Infektion, disseminierte intravasale Gerinnung, Körpergewicht/größe, Thrombozytenantikörper, Anzahl vorangegangener Thrombozytentransfusionen, Medikation, z. B. Heparin, Amphotericin B) [114]. Heim et al. identifizierten folgende Patientenfaktoren, welche die CCI-Werte beeinflussen: Alter, Geschlecht, Therapie der Grundkrankheit und Anzahl der Vortransfusionen [97]. CCI-Werte waren höher bei jüngeren Patienten $(<10$ Jahre) und niedriger bei Patienten älter als 40 Jahre. Empfänger eines allogenen Stammzelltransplantats hatten einen signifikant schlechteren Thrombozytenanstieg als Patienten, welche nur mit Chemotherapie behandelt wurden [97]. Inverardi et al. zeigten, dass Patientenfaktoren einen größeren Einfluss auf die CCI-Werte haben als das Herstellungsverfahren der TK. Patienten mit negativen Einflussfaktoren (Fieber, Bakteriämie, Blutung, Koagulopathie, Stammzelltransplantation, bestimmte Medikamente) hatten sowohl nach ATK als auch nach PTK einen schlechten Thrombozytenanstieg. Nach Beseitigung der negativen Einflussfaktoren konnte mit beiden Präparatetypen wieder ein gutes Inkrement erreicht werden [115].

Die Untersuchungen zur in vivo Wirksamkeit basieren mehrheitlich auf dem Surrogatparameter CCI. 2008 wurde ein 


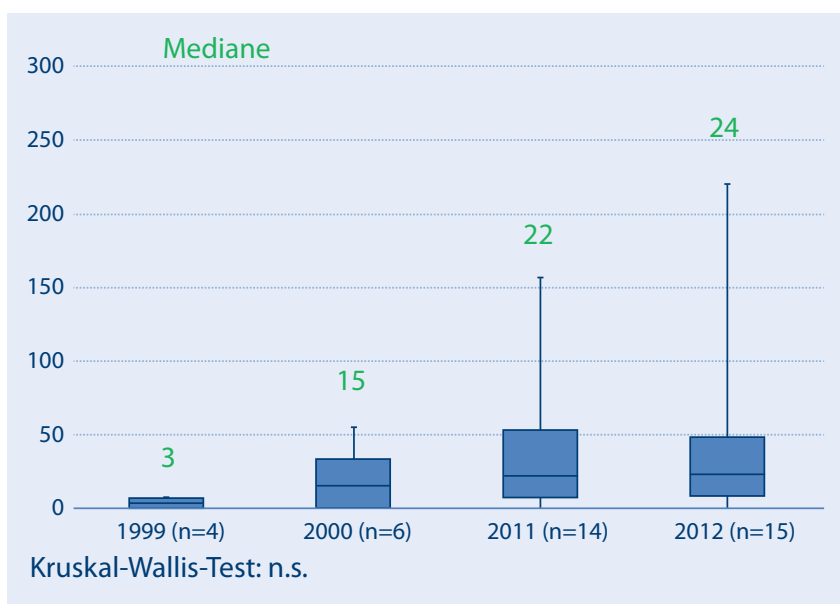

Abb. $1<$ Anzahl Anforderungen für typisierte TK/1000 hergestellte TK pro Einrichtung systematischer Review publiziert mit dem Ziel, die Wirksamkeit und Sicherheit von ATK und PTK vergleichend zu bewerten [110]. In diese Metaanalyse konnten 10 randomisierte, kontrollierte Studien einbezogen werden, von denen jedoch 5 nach Meinung der Autoren des systematischen Reviews nur eine mäßige Qualität aufwiesen. Es zeigte sich ein signifikant besserer CCI nach einer Stunde und nach 12-24 h Transfusion von ATK. Jedoch ist zu beachten, dass die meisten PTK mit der PRP-Methode hergestellt wurden. Im Vergleich von ATK und BC-PTK zeigte sich kein signifikanter Unterschied. Allerdings liegen hierzu nur wenige Studien vor. In allen anderen untersuchten Aspekten (Blutungsereignisse, akute Transfusionsreaktionen, Alloimmunisierung, Refraktärität und Zeit bis zur nächsten Transfusion) fanden die Autoren keine signifikanten Unterschiede zwischen ATK und PTK (unabhängig von der PTK-Herstellungsmethode). Insgesamt fanden die Autoren eine sehr heterogene Datenlage und plädierten für die Durchführung von kontrollierten, randomisierten Studien zur abschließenden Beurteilung der Wirksamkeit von ATK und PTK. Da ATK in Deutschland mehrheitlich noch in $100 \%$ Plasma suspendiert werden, während die BC-PTK in der Regel mit additiver Lösung hergestellt werden, stellt der Vergleich von PTK und ATK einen kombinierten Vergleich der Thrombozytengewinnung (Vollblut vs. Apherese) und der Suspensionslösung (Plasma vs. additive Lösung) dar [6]. Darüber hinaus ist zu beachten, dass die oben zitierten Studien bei Patienten mit hyporegenerativen
Thrombozytopenien durchgeführt [112] wurden und nicht ohne weitere Studien auf andere Empfängergruppen (z. B. Patienten mit akuten Blutungen) übertragen werden können.

In der Gesamtbetrachtung aller Publikationen zeigt sich, dass keine ausreichenden Daten aus prospektiv-randomisierten Studien zu einer gleichwertigen oder unterschiedlichen therapeutischen Wirksamkeit von PTK (buffy coat) und ATK vorliegen [112].

\subsection{Anforderungen von typisierten TK für refraktäre Patienten}

Patienten mit HLA- oder HPA-Alloimmunisierung benötigen ATK von HLAoder HPA-ausgewählten Spendern. Die Meldedaten nach $\$ 21$ TFG erfassten bislang den Anteil typisierter TK für spezielle Indikationen nicht. Daher wurden alle deutschen Blutspendeeinrichtungen (BSE) befragt, wie viele Anforderungen für typisierte TK bezogen auf die Gesamtherstellung an TK in den 2 Jahren vor Einführung der universellen Leukozytendepletion und in den Jahren 2011 und 2012 seitens der Kliniken vorlagen. Insgesamt haben 21 BSE geantwortet. Die Abbildung zeigt eine große Spannbreite für die Einrichtungen. Aus dem Jahr 1999 lagen kaum Informationen vor. Der Median an angeforderten typisierten TK pro 1000 hergestellten TK ist nach Einführung der universellen Leukozytendepletion gestiegen und lag in den Jahren 20112012 bei 22-24 Anforderungen/1000 TK (Zahlen von insgesamt 17 Einrichtungen, - Abb. 1).
Für das Meldejahr 2013 wurde die Abfrage an die Anwender nach $\$ 21$ TFG um die Angabe zum Verbrauch und Verfall an typisierten TK erweitert. Der für ganz Deutschland gemeldete Anteil des Verbrauchs an typisierten TK entspricht dabei in der Größenordnung dem Median aus den o. g. Angaben von ausgewählten Kliniken (• Tab. 1).

Es gibt Daten aus Studien, die eine Verringerung der Alloimmunisierung durch Leukozytendepletion belegen [107], ebenso Daten, die zeigen, dass durch eine Leukozytendepletion vor der Lagerung die febrilen nicht-hämolytischen Transfusionsreaktionen signifikant verringert werden können [6]. Entsprechend wäre zu erwarten, dass der Bedarf an typisierten TK für vorimmunisierte Patienten nach Einführung der universellen Leukozytendepletion in Deutschland zurückgegangen ist. Da die Tendenz anhand der erfassten Daten gegenläufig ist, sind zusätzliche Aspekte für die Auswahl typisierter TK anzunehmen. Hierbei ist die deutliche $\mathrm{Zu}$ nahme von Behandlungen bei hämatologisch/onkologischen Erkrankungen mit Stammzell-Support und häufigerer TKSubstitution von Bedeutung. In einzelnen Einrichtungen wird nach persönlicher Information auch die grundsätzliche Gabe von typisierten TK zur Vermeidung einer Immunisierung bei diesem Patientenkollektiv bevorzugt. Hier besteht Forschungsbedarf zur Frage, ob dies den gewünschten Effekt erzielt.

\section{Risiken für Transfusionsempfänger}

\subsection{Infektionsrisiken}

Ein entscheidender Aspekt bei der Betrachtung von ATK und PTK ist die Bewertung der Infektionsrisiken durch die Präparate. Blutprodukte in Deutschland sind durch die strikte Spenderauswahl und die konsequente Testung sowie die sachgerechte Herstellung so sicher wie noch nie. Dennoch bestehen Restrisiken durch bekannte und unbekannte Erreger.

Diese transfusionsbedingten Risiken, insbesondere die von nicht bekannten Erregern, quantitativ abzuschätzen ist schwierig, da selbst bei bekannten Erregern keine $100 \%$ ige Nachverfolgung und 
Tab. 1 Meldung nach $\S 21$ TFG zu ange-

wendeten bzw. beim Anwender verfalle-

nen TK für das Jahr 2013

\begin{tabular}{|ll}
\hline TK angewendet & 482.200 \\
\hline Davon verfallen & 26.801 \\
\hline Entspricht \% verfallene TK & 5,56 \\
\hline TK angewendet, davon typisiert & 17.149 \\
\hline Entspricht \% typisierte TK & 3,56 \\
\hline Verfall typisierte TK & 212 \\
\hline $\begin{array}{l}\text { Entspricht \% verfallene typi- } \\
\text { sierte TK }\end{array}$ & 1,24 \\
\hline $\begin{array}{l}\text { Entspricht \% verfallene TK ins- } \\
\text { gesamt }\end{array}$ & 0,04 \\
\hline
\end{tabular}

Erfassung von Reaktionen bei Transfusionsempfängern erfolgt. Zur Abschätzung von Risiken stehen daher Hämovigilanzdaten und mathematische Modelle zur Verfügung.

Zentral für die Diskussion der Herstellungsverfahren für TK ist die erhöhte Spenderexposition bei PTK, die durch die in der Regel 4 Spender entsteht, die zur Herstellung eines PTK beitragen. Zur Frage des aus dieser erhöhten Spenderexposition resultierenden Risikos und dessen Relevanz für die Transfusionsempfänger sind bereits mehrere, $z$. T. kontroverse Publikationen erschienen $[6,38$, $116,117]$. Häufig wird, insbesondere für unbekannte Erreger, die Anzahl der Spenden für die PTK (vier) mit dem Faktor der Risikoerhöhung gleichgesetzt. Einige Autoren postulieren sogar noch höhere Risiken, wenn es gelingt, einen Patienten mit den 2-3 Produkten aus einer Apherese zu versorgen [116]. In diesem Fall würde das Risiko für eine Infektion unter bestimmten Annahmen bis zu 12-mal höher liegen als bei einem (bzw. drei) ATK eines Spenders. Dieses erhöhte Risiko wird im Kontext der übrigen risikominimierenden Maßnahmen als nicht akzeptabel angesehen und resultiert in der Forderung, ausschließlich ATK anzuwenden [38, 116]. Grundlage für diese Ansicht ist das so genannte Vorsorgeprinzip, das darauf abzielt, trotz fehlender Gewissheit bezüglich Art, Ausmaß oder Eintrittswahrscheinlichkeit von möglichen Schadensfällen vorbeugend $\mathrm{zu}$ handeln, um diese Schäden von vornherein zu vermeiden.

Tab. 2 Meldehäufigkeit von definierten Transfusionsreaktionen nach Anwendung von ATK und PTK (Hämovigilanzdaten 1997-2011)

\begin{tabular}{|c|c|c|}
\hline \multirow{2}{*}{$\begin{array}{l}\text { Identifizierte Risiken nach Einführung risikominimierender } \\
\text { Maßnahmen }^{\mathrm{a}}\end{array}$} & \multicolumn{2}{|c|}{ Häufigkeit: Fälle/10 $10^{6} \mathrm{TK}$} \\
\hline & PTK & ATK \\
\hline ATR (Akute/Allergische Transfusionsreaktion) & 40 & 40 \\
\hline TBBI (Transfusionsbedingte Bakterielle Infektion) & 6 & 6 \\
\hline TRALI (Transfusion Related Acute Lung Injury) & 3 & 3 \\
\hline HTR (Hämolytische Transfusionsreaktion) & 2 & 2 \\
\hline TACO (Transfusions-Associated Circulatory Overload) & 3 & 3 \\
\hline TB- HBV (Transfusionsbedingte HBV-Infektion) ${ }^{\mathrm{b}}$ & 0 & 0,6 \\
\hline \multicolumn{3}{|c|}{$\begin{array}{l}\text { aDie Meldehäufigkeit von Transfusionsreaktionen (Spendertestung, Spenderausschluss, Pre-donation Sampling, } \\
\text { etc.) bezieht sich auf den Zeitraum nach der Einführung der Maßnahme. } \\
\text { bHIV-Transmissionen wurden in dem Zeitraum 1997-2011 bei TK-Gaben nicht gemeldet, die letzten HCV-Trans- } \\
\text { missionen nach TK-Gabe wurden in den Jahren 1998/1999 gemeldet. }\end{array}$} \\
\hline
\end{tabular}

\subsubsection{Hämovigilanzdaten}

Auf gesetzlicher Grundlage sind die behandelnden Ärzte dazu verpflichtet, im Falle des Verdachts der unerwünschten Reaktion oder Nebenwirkung eines Blutproduktes unverzüglich den pharmazeutische Unternehmer und im Falle des Verdachts einer schwerwiegenden unerwünschten Reaktion oder Nebenwirkung eines Blutproduktes und eines Plasmaproteinpräparates zusätzlich die zuständige Bundesoberbehörde zu unterrichten $[118,119]$. Hierbei handelt es sich jedoch um so genannte Spontanmeldungen, die erfolgen, wenn bei einem transfundierten Patienten unerwünschte Wirkungen bekannt werden. Ergänzt werden die Spontanmeldungen durch Daten aus Rückverfolgungsverfahren gemäß $\$ 19$ TFG, die auch eine aktive Fallsuche nach Identifizierung eines infektiösen Spenders beinhalten $[120,121]$. Auch Daten aus der mikrobiologischen Qualitätskontrolle an Stichproben können für den Anteil bakterieller Kontaminationen von Produkten herangezogen werden.

\subsubsection{Unerwünschte Reaktionen nach TK Transfusion}

Die deutschen Daten zur Hämovigilanz stammen aus den Meldungen gemäß $\$ 63$ i AMG. In einem Hämovigilanzsystem kann nicht die Gesamtheit aller schwerwiegenden Transfusionsreaktionen erfasst werden. Somit lässt sich zwar die Meldehäufigkeit für einzelne Reaktionen, nicht aber deren Inzidenz ermitteln. Die Meldehäufigkeit wird zudem durch die Sensibilisierung für spezifische Transfusionskomplikationen beeinflusst, so dass es bei einem längeren Beobachtungs- zeitraum zu einer Veränderung des Meldeverhaltens kommen kann. Diese Einflussgrößen müssen bei der Beurteilung des Nutzens von Maßnahmen zur Verbesserung des Sicherheitsstandards berücksichtigt werden. Insgesamt lässt sich jedoch mit Hilfe der Hämovigilanzdaten eine Entwicklung (Trend) von Transfusionsrisiken beschreiben und durch eine gezielte Auswertung auch der Nutzen von risikominimierenden Maßnahmen abschätzen.

Im Folgenden werden die gemeldeten Transfusionsreaktionen in Form der Meldehäufigkeit identifizierter Risiken bezogen auf den Vertrieb pro $10^{6}$ Thrombozytenkonzentraten dargestellt (• Tab. 2).

Aus den oben genannten Betrachtungen ergibt sich, dass die Melderaten insbesondere für schwerwiegende unerwünschte Transfusionsreaktionen nahezu vollständig sind. Anhand der Übersicht in $\bullet$ Tab. 2 wird aber auch deutlich, dass die Übertragung von Infektionserregern durch Blutkomponenten ein sehr seltenes Ereignis ist. Obwohl die grundsätzliche Aufmerksamkeit für Erreger wie vCJD-Prionen und das West Nil Virus (WNV) durch die Präsenz in der Öffentlichkeit vorhanden sein sollte, wurde bislang noch kein Fall einer Übertragung durch diese in Deutschland seltenen oder durch neue, noch unbekannte Erreger gemeldet.

Bezogen auf die ermittelte Meldehäufigkeit findet sich kein relevanter Unterschied zwischen den beiden Herstellungsmethoden für Thrombozytenkonzentrate.

Bezüglich möglicher bzw. zukünftiger Risiken lässt sich aufgrund der Hämovigilanzdaten keine Aussage machen. Dies 


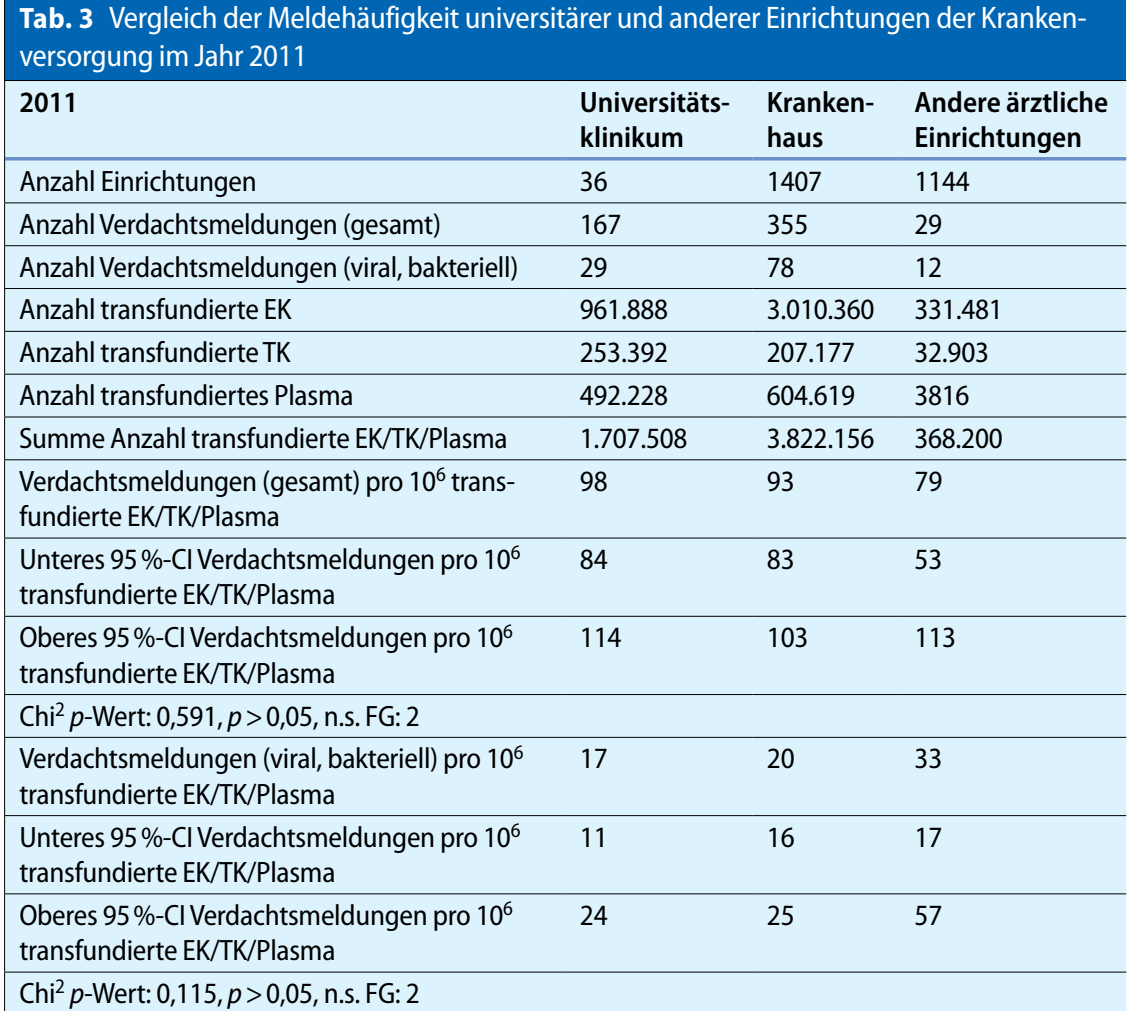

gilt in gleicher Weise für beim Empfänger nicht untersuchte Erreger bzw. nicht dokumentierte Erkrankungen.

\subsubsection{Meldeverhalten bei Nebenwirkungen}

Der Grad der Vollständigkeit der Spontanmeldungen aus Einrichtungen der Krankenversorgung ist unbekannt. In einem europäischen Survey, an dem sich 23 EU-Mitgliedstaaten beteiligten, gaben vier Staaten an, von $100 \%$ der Einrichtungen der Krankenversorgung Meldungen zu erhalten, 10 berichteten, dass median 76\% (47-96\%) der Einrichtungen meldeten, und 9 konnten den Anteil der meldenden Einrichtungen nicht quantifizieren [122]. Für Deutschland sind solche Daten im Einzelnen nicht bekannt. Bei den Spendeeinrichtungen kann aufgrund der guten Meldecompliance bei den anderen verpflichtenden Meldungen [123-125] von einer guten Erfassung ausgegangen werden. Bei den Einrichtungen der Krankenversorgung ist auch eine gute Meldehäufigkeit anzunehmen, wenn die Nebenwirkung an sich als transfusionsassoziiert erkannt wird. Bei schwerwiegenden Nebenwirkungen ist auch hier anzunehmen, dass die Meldungen eine hohe Vollständigkeit haben. Bei nicht schwerwiegenden Nebenwirkungen ist der Grad der Untererfassung vermutlich größer. Ein unterschiedliches Meldeverhalten der behandelnden Ärzte in universitären und nicht-universitären Einrichtungen könnte jedoch einen Einfluss auf die Melderate der untersuchten Thrombozytenkonzentrate bezüglich transfusionsbedingter Infektionen haben. Um eine Abschätzung des Meldeverhalten vornehmen zu können, werden in der folgenden Tabelle (• Tab. 3) le einer schwerwiegenden unerwünschten Reaktion sowie einer transfusionsbedingten Infektion (Meldungen nach $\$ 63 i$ AMG) im Kalenderjahr 2011 der Anzahl der transfundierten Blutkomponenten (Meldungen gemäß $\$ 21$ TFG) in den entsprechenden Einrichtungen gegenübergestellt. Bei der Ermittlung der Meldehäufigkeiten bezogen auf die angewendete Anzahl an Blutkomponenten (EK, TK und therapeutische Einzelplasmen) lässt sich für das untersuchte Jahr kein signifikanter Unterschied zwischen universitären und nicht-universidie Anzahl der gemeldeten Verdachtsfäl- tären Einrichtungen nachweisen. Eine Verzerrung (Bias) zu Ungunsten einer der beiden Herstellungsprozesse kann aufgrund dieser Daten nicht angenommen werden.

\subsubsection{Bakterielle Kontamination}

Bakterielle Kontamination von Thrombozytenkonzentraten stellt ein relevantes Restrisiko dar und übersteigt das Risiko einer Übertragung eines bekannten viralen Erregers [126-133]. Die Hauptursache der bakteriellen Kontamination sind Kontamination im Rahmen der Venenpunktion des Spenders oder Bakteriämie des Spenders. Kontamination der Beutelsets, Filter oder additiver Lösungen oder exogene Kontaminationen im Rahmen der Verarbeitung der Blutspende sind sehr selten. Daher könnte angenommen worden, dass ein Pooling der "Buffy Coats“ das Risiko der bakteriellen Kontamination entsprechend der Anzahl gepoolter Einheiten erhöht. Es konnte jedoch in "Spiking-Experimenten“, d. h. experimenteller bakterieller Kontamination der Spende, gezeigt werden, dass die initiale bakterielle Kontamination einer Vollblutspende bei Herstellung von PTK um mehrere Log-Stufen abnimmt, wahrscheinlich aufgrund der Phagozytose-Aktivität von Leukozyten in der Spende [134]. Mehrere Studien analysierten die bakterielle Kontaminationsrate in einer großen Zahl von Thrombozytenkonzentraten, welche mit unterschiedlichen Methoden hergestellt wurden (mit/ohne predonation sampling; ATK vs. PTK; Plasma/additive Lösung;) [27, 135-145]. Diese Studien konnten übereinstimmend kein höheres Kontaminationsrisiko von ATK im Vergleich zu PTK nachweisen. Eine frühere Studie, welche im Vergleich der Kontaminationsraten in sequentiellen Perioden für ATK ein niedrigeres Kontaminationsrisiko postulierte [131], konnte somit in diesen Studien mit einem direkten Vergleich von ATK und PTK nicht bestätigt werden.

Eine prospektive Studie verglich die Kontaminationsrate von über 15.000 ATK und mehr als 37.000 PTK, welche in deutschen Blutspendeeinrichtungen hergestellt wurden und mit aeroben und anaeroben Kulturverfahren untersucht wurden. Bei PTK war die Rate potentiell positiver Präparate niedriger als bei ATK. Die 
Rate bestätigt positiver Präparate war nicht signifikant unterschiedlich [140]. Studien aus anderen Ländern zeigten analoge Ergebnisse [135-138].

In den letzten Jahren wurden verschiedene Strategien verfolgt, um das Risiko einer bakteriellen Kontamination zu vermindern: Spenderauswahlkriterien, um Spender mit erhöhtem Risiko für Bakteriämie auszuschließen; verbesserte Hautdesinfektion vor der Venenpunktion, standardisierte Prüfung von sterilen Schlauch-Schweißverbindungen, „predonation sampling“ und Verkürzung der Haltbarkeit von TK. Die Wirksamkeit dieser Maßnahmen zur Reduktion der bakteriellen Kontamination wurde in mehreren Studien belegt [146-151]. Die Möglichkeiten, die bakterielle Sicherheit durch Testverfahren zu verbessern, werden inzwischen erprobt und sind Gegenstand von Studien [136, 137, 141, $152-$ 155].

\subsubsection{Mathematische Modelle zur Risikoschätzung}

$\mathrm{Da}$ es sich insbesondere bei den Infektionsübertragungen um sehr seltene Ereignisse handelt, ist es selbst bei einem gut etablierten Hämovigilanzsystem schwer, eine absolut verlässliche Aussage zum Risiko zu treffen. Hämovigilanzdaten erlauben zudem nur eine rückblickende Bewertung. Daher sind mathematische Modelle entwickelt worden, um die Wahrscheinlichkeit einer unerkannt infektiösen Spende zu schätzen. Die Schätzung begrenzt sich meist auf das Fensterphasenrisiko, das heißt das Risiko, dass eine Infektion in ihrer Frühphase von den verwendeten Screening-Tests (noch) oder bei unbekannten oder nicht getesteten Erregern vor Auftreten von Symptomen nicht erkannt wird. Infektiöse Risiken, die sich durch Fehler bei der Herstellung oder Ausgabe der Blutprodukte oder durch die fehlerhafte Anwendung von Testen ergeben, können durch diese Modelle nicht hinreichend abgebildet werden. Für die Schätzung wird in dem gängigsten Modell, dem so genannten incidence rate/window period model (IR/WP-Modell) [156] angenommen, dass die Anzahl der unerkannt infektiösen Spenden proportional zur Inzidenz der Infektionen und der Länge der Fensterphase ist. Dieses gut handhabbare
Modell ist geeignet, eine Abschätzung der Wahrscheinlichkeit von Fensterphasenspenden vorzunehmen, wenn die Spendeprozesse, insbesondere die Spendenintervalle, vergleichbar homogen verteilt sind, z. B. bei Vollblutspenden. Bei Restrisikomodellen ist die angenommene Dauer der Fensterphase der Term in der Gleichung, der besonders wichtig ist. Daher werden bei Unterschieden in den angenommenen Fensterphasen $[157,158]$ z. T. sehr unterschiedliche absolute Restrisiken berechnet. Es ist daher bei der Beurteilung von Angaben zum Restrisiko immer wichtig zu prüfen, ob die verwendeten Methoden vergleichbar sind [159]. Die unten dargestellten Restrisiken verwenden eine konservative Schätzung für die Dauer der Fensterphase.

\subsubsection{Restrisiko durch HIV, Hepatitis-C (HCV)- und Hepatitis-B (HBV)-Infektionen}

Für die getesteten viralen Infektionen in Deutschland mit HIV, HCV und HBV sind Restrisikoschätzungen für Vollblutspenden vorgenommen worden [158, $160,161]$. Diese ergaben zuletzt geschätzte Restrisiken für eine unerkannt infektiöse Spende von 1:4,3 Mio. für HIV, 1:10,9 Mio. für HCV und 1:360.000 für HBV [158].

Für die vergleichende Analyse von verschiedenen Spendeprozessen (wie Vollblut - und Apheresespenden) ist das IR/ WP-Modell weniger geeignet, da es eine Annahme über die Verteilung der durchschnittlichen Spendeintervalle enthält. Wenn das IR/WP-Modell weiterentwickelt wird, können beim Vorliegen konkreter Surveillancedaten von Spendern die tatsächlichen Spendeintervalle berücksichtig werden [162, 163].

Dieses Modell ist präziser, weil es mit weniger Annahmen auskommt.

Für die vergleichende Analyse von Risiken durch HIV, HCV und HBV-Infektionen durch ATK und PTK wurden beide beschriebenen Modelle eingesetzt. Verwendet man das IR/WP-Modell, so zeigt sich für die genannten Infektionen ein höheres Restrisiko für PTK für alle 3 Infektionen. Die relative Steigerung des Risikos lag für HIV bei 2,2, für HCV bei 2,7 und für HBV bei 3,2 für das Jahr 2011 [38, 164]. Bei der Betrachtung der Daten fällt auf, dass die vermutete Risikoerhöhung um den Pooling-Faktor 4 nicht eintrat, da die Spenderpopulationen sich insbesondere hinsichtlich Alter, Geschlecht und Spendenort (Groß- oder Kleinstadt) unterschieden $[125,160,161]$. Daten der Surveillance nach Infektionsschutzgesetz zeigen, dass sich Infektionen nicht gleichmäßig in der Bevölkerung verteilen [165-167]. Diese unterschiedlichen Häufigkeiten der betrachteten Infektionen spiegeln sich auch in der selektierten Spenderpopulation wider. Daher reduzieren sich die gefundenen Risikounterschiede gegenüber dem reinen Pooling-Faktor.

Das „klassische“ WP/IR-Modell beinhaltet die Annahme eines mittleren Spendeintervalls für beide Spendenarten und schätzt die Inzidenz unter den Spendern. Da die Spendeintervalle jedoch unterschiedlich sind, wurde dieses Modell weiterentwickelt. So konnten die konkreten Spendeintervalle, die im Rahmen der Spendersurveillance gemeldet werden [163], verwendet werden und es war möglich, auf eine weitere Annahme zu verzichten. Für diesen Ansatz wird die Wahrscheinlichkeit berechnet, dass die letzte negative Spende vor einer positiven Spende eine Fensterphasenspende war. Diese Wahrscheinlichkeit ist erhöht, wenn das Spendenintervall kurz ist. Grundsätzlich besteht in Deutschland ein Mindestspendeintervall von 56 Tagen für Vollblutspenden, im Mittel spenden Vollblutspender zweimal im Jahr $[13,168]$. Gemäß Hämotherapie-Richtlinien sind innerhalb von 12 Monaten bis zu 26 Thrombozytapheresen möglich; es können auch Zyklen von täglichen Thrombozytapheresen ohne gleichzeitige Plasmapheresen über bis zu 5 Tage durchgeführt werden. Nach einem 5-Tage-Zyklus ist bis zur nächsten Einzelspende ein Abstand von mindestens 14 Tagen einzuhalten. Ein erneuter 5-Tage-Zyklus ist unter besonderer Beachtung der Thrombozytenwerte frühestens nach 3 Monaten möglich. Dividiert man die Anzahl aller im Rahmen der Spendervigilanz gemeldeten Thrombozytapheresespenden durch die Anzahl der Spender, so ergibt sich eine gemittelte Anzahl von 5 Zytapheresespenden/Jahr. Dieser Wert bildet jedoch nicht die tatsächlichen Spendeintervalle ab und berücksichtigt nicht die Verteilung der Spenden- 
häufigkeit [168]. Bei der Analyse der letzten 3 Spendeintervalle der positiv getesteten Spender zeigte sich, dass z. T. kurze Spendeintervalle auftreten: Von 56 betrachteten Spendeintervallen waren 19 kürzer als 21 Tage, 4 kürzer als 10 Tage.

Die vergleichende Schätzung des Restrisikos für die getesteten Erreger mit dem weiterentwickelten Modell lag pro Million Produkte für den Zeitraum 20062012 für HIV bei 2,08 für PTK und 1.7 für ATK, für HCV bei 1,4 für PTK und 0,9 für ATK, für HBV bei 4,3 für PTK und 6,9 für ATK. Die resultierenden Risikoverhältnisse waren für HIV nicht signifikant $(0,82,95 \%$ CI: 0,60-1,08), signifikant für $\operatorname{HCV}(0,66,95 \%$ CI: $0,45-0,77)$ und HBV (1,62, 95 \% CI: 1,36-1,93). Entsprechend ergibt die Schätzung, dass mehr unerkannt HCV-infektiöse PTK (Faktor 1,5) und mehr HBV-infektiöse ATK (Faktor 1,6) auftreten, bei HIV-Infektionen ist der Unterschied nicht signifikant (Faktor 1,2). Dies sind Schätzungen auf der Basis konkret übermittelter Surveillancedaten von Spendern in Deutschland. Die geschätzten Risikounterschiede resultieren in erster Linie aus den Inzidenzen der genannten Infektionen in den unterschiedlichen Spenderpopulationen. ATK-Spender sind eher männlich, jung und spenden in Großstädten. Weiterhin steigt wie oben dargelegt die Wahrscheinlichkeit einer Fensterphasenspende abhängig von der Länge der Fensterphase, je kürzer die Spendeintervalle sind.

Veränderungen dieser Parameter der Schätzung würden diese entsprechend beeinflussen. Wenn man zum Beispiel im Modell fiktiv die tatsächlich gemeldeten Spendenintervalle für die positiv getesteten ATK-Spender auf mindestens 30 Tage festsetzt, so ergeben sich höhere geschätzte Risiken für PTK: Die resultierende Risikoschätzung mit diesen Annahmen ergibt, dass mehr unerkannt HIV-infektiöse PTK (Faktor 1,65) und mehr HCV-infektiöse PTK (Faktor 3,9) auftreten. Bei HBV-Infektionen ist der Unterschied nicht signifikant (Faktor 1,08). Somit nähern sich diese Schätzungen mit fiktiv längeren Spendeintervallen für die beobachteten infektiösen ATK-Spender auch mit dem weiterentwickelten Modell den Restrisikoschätzungen mit dem einfacheren IR/WP-Modell.
Infektionsrisiken verteilen sich unabhängig von der Spendenart nicht gleichmäßig in der Spenderpopulation. Dementsprechend haben nicht alle nicht-inaktivierten Blutprodukte humanen Ursprungs dasselbe Risiko für eine transfusionsassoziierte Infektion. Dies ist für die Bewertung der geschätzten Risiken für bekannte Erreger von Interesse. Beispielsweise ist seit vielen Jahren die HIVInzidenz bei männlichen Spendern signifikant höher als bei weiblichen Spendern $[125,169,170]$. Wendet man die Risikoschätzung für Vollblutspenden auf diese beiden Subgruppen an, so wird das HIVRisiko bei männlichen Spendern um den Faktor sieben höher geschätzt [164]. Die geschätzten Risikounterschiede zwischen ATK und PTK liegen somit, auch mit dem IR/WP-Modell, innerhalb der bekannten und akzeptierten intrinsischen Risikoschwankungen für bekannte Erreger in labilen Blutkomponenten.

\subsubsection{Risiken von unbekannten oder nicht getesteten Erregern}

Für die Abschätzung des Risikos eines bislang unbekannten Erregers können grundsätzlich die vereinfachten Restrisikomodelle verwendet werden. Hierbei sind jedoch über die Inzidenz und die Fensterphase hinaus weitere relevante aber unbekannte Größen zu beachten. Entscheidende Parameter in der Abschätzung betreffen die Erregereigenschaften, den Übertragungsweg, die Empfängereigenschaften und die Eigenschaften des Blutprodukts. Darüber hinaus sind Populationsaspekte wie allgemeine Durchseuchung und Krankheitslast und die Notwendigkeit von Transfusionen von grundsätzlicher Relevanz.

- Bei den Erregereigenschaften sind insbesondere die „Attack rate“, die nötige Infektionsdosis, die Effektivität der parenteralen Übertragung, die Dauer der Pathogenämie und die grundsätzliche Nachweisbarkeit durch Testverfahren oder Erkennbarkeit durch klinische Symptome von Relevanz.

- Der Übertragungsweg (z. B. Nahrungsmittel-assoziiert, sexuell, ausschließlich parenteral, Vektor-gebunden, respiratorisch, durch direkten
Kontakt) wird die Bevölkerungsgruppen bestimmen, die am ehesten exponiert sind. Auch unbekannte Erreger verteilen sich nicht gleichmäBig in der Allgemein- oder Spenderpopulation.

- Die Empfänglichkeit der Empfängerpopulation für die Infektion und die Wahrscheinlichkeit einer Erkrankung können z. B. abhängig vom Immunstatus oder von genetischen Prädispositionen sein. So könnten Immunsupprimierte besonders schwere Krankheitsverläufe haben oder einige Empfänger kreuzreagierende protektive Antikörper aufweisen.

- Bei den spezifischen Produkteigenschaften sind neben den Parametern, die in die Restrisikoschätzmodelle eingehen wie Spendenhäufigkeit, Spenderexposition und Inzidenz in der Spenderpopulation, insbesondere Aspekte der Herstellung wie Anteil des Plasmas im TK, Verdünnungseffekte beim Poolen und beim Vorliegen von protektiven Antikörpern deren Effektivität von Bedeutung.

Naturgemäß sind Restrisikomodelle aufgrund ihrer Annahmen immer mit vielen Unsicherheiten behaftet. Wird die Anzahl der Annahmen, die in das Modell einfließen größer, so steigt auch die Unsicherheit der Aussagekraft. Dies wird deutlich, wenn man sich die Abschätzungen für die vCJK-Epidemie über die Zeit ansieht [171-173]. Die initialen Befürchtungen, dass eine ausgedehnte Epidemie auftreten könnte, haben sich glücklicherweise nicht bestätigt und konnten, je mehr konkrete Surveillancedaten vorlagen, präzisiert werden.

Für die Abschätzung des Risikos der Übertragung eines unbekannten Erregers durch ATK bzw. PTK sind grundsätzlich alle Szenarien denkbar: Das Risiko bei PTK könnte maximal um den Faktor des Poolens (in Deutschland in der Regel vier) erhöht sein oder durch Verdünnungseffekte/vorhandene Antikörper im Plasma, längere Spendeintervalle oder unterschiedliche Spenderpopulationen bei PTK gleich oder geringer sein als bei ATK.

Als Beispiel eignet sich die HepatitisE-Virus (HEV)-Infektion. Aktuell wer- 
den Spenden nicht verpflichtend getestet und infektiöse Spender können aufgrund der unspezifischen oder fehlenden Symptomatik nicht sicher durch die Spenderauswahl erkannt werden. In einer großen retrospektiven Untersuchung in Großbritannien wurden 225.000 Spenden aus den Jahren 2012 und 2013 retrospektiv auf das Vorhandensein von HEV-Genom untersucht [174]. 43 Empfänger der Blutprodukte konnten nachuntersucht werden. Von den 43 Empfängern erhielten 10 ein PTK und 14 ein ATK. 4 der 10 PTKEmpfänger und 7 der 14 ATK-Empfänger zeigten Zeichen einer HEV-Infektion. In dieser Untersuchung resultierte die erhöhte Spenderexposition nicht in einer erhöhten Infektionsrate.

\subsubsection{Exposition gegenüber Spendern bezogen auf die Behandlung}

Man kann Restrisiken bezogen auf Produkt, Herstellungsverfahren oder das Gesamtrisiko aller applizierten Blutprodukte bei einem einzelnen Patienten betrachten bzw. abschätzen.

Die dargestellten mathematischen Modelle schätzen das Risiko einer unerkannt infektiösen Spende, die sich bei Kenntnis der Herstellungsverfahren in das Risiko für ein Produkt übersetzen lässt. Ein wichtiger Aspekt hierbei ist die Spenderexposition, die in den aktuellen Diskussionen häufig quantitativ mit Infektionsrisiken gleichgesetzt wird [38, 116]. Grundsätzlich sind alle Hämotherapeuten bestrebt, die Exposition gegenüber Medikamenten und Medizinprodukten allogenen humanen Ursprungs zu verringern, um mögliche infektiöse und nicht-infektiöse $\mathrm{Ne}$ benwirkungen so gering wie möglich $\mathrm{zu}$ halten. Jedoch ist bei dieser Betrachtung auch die Gesamtexposition im Rahmen einer Behandlung von Interesse. Die Rationale hierbei ist, dass insbesondere hämatologisch-onkologische Patienten, die aktuell 75\% der hergestellten TK erhalten, in der Regel auch andere Blutkomponenten transfundiert bekommen. Eine große Kohortenstudie an zwei großen Einrichtungen der Krankenversorgung zeigte, dass in dem beschriebenen Patientenkollektiv die Spenderexposition bei Verwendung von PTK aus vier Spenden insgesamt um im Mittel 44\% gegenüber der Verwendung von ATK erhöht war und nicht um den Faktor vier, der für das Poolen angesetzt war [175]. Auch in älteren Studien mit anderen Studienzielen wurde gezeigt, dass die Spenderexposition bei Patienten mit akuter Leukämie die Gesamtspenderexposition unter Berücksichtigung von EKund TK-Transfusionen in dem gegebenen Studienprotokoll bei der Transfusion von ausschließlich PTK etwas mehr als doppelt so hoch lag wie bei ausschließlicher Transfusion von ATK, jedoch auch nicht bei dem Faktor vier lag [107].

\subsubsection{Punktuelle Risiken}

In Restrisikoschätzmodellen wird das gemittelte Risiko dargestellt. Das konkrete Restrisiko kann jedoch auch punktuell auftreten. Hierbei ist zu beachten, dass aus einer ATK-Spende häufig 2 oder 3 Produkte hergestellt werden und auch grundsätzlich kurze Spendeintervalle vorkommen können (s.o.). Bei den PTK können hingegen die weiteren Komponenten der Spende (EK, FFP) ebenfalls infektiös sein. Dass dies nicht nur in der Theorie Folgen hat, zeigen zwei Hepatitis-E-Virus (HEV)-Übertragungen durch TK im Jahr 2013. Aktuell werden die Spenden nicht verpflichtend auf HEV getestet und in Immunkompetenten verläuft die Infektion häufig asymptomatisch, so dass die infektiösen Spender nicht durch die Spenderauswahlkriterien erkannt werden. In einem Fall wurde die Infektion durch ein PTK verursacht. Das aus der Spende ebenfalls hergestellte EK wurde nicht in den Verkehr gebracht. Die Infektion beim Empfänger des TK verlief asymptomatisch. Im zweiten Fall war ein ATKSpender infektiös. Er leistete 2 infektiöse ATK-Spenden im Abstand von 14 Tagen, aus denen insgesamt 6 ATK hergestellt wurden. Ein Stammzell-transplantierter Empfänger infizierte sich durch das ATK und verstarb an einem Leberversagen bei schwerer Graft versus HostReaktion $(\mathrm{GvH})$ mit Leberbeteiligung. Bei dem Versuch, die HEV-Infektion zu behandeln wurde die Immunsuppression reduziert, was die GvH verstärkte. Die Todesursache war nicht monokausal, jedoch hat die HEV den Verlauf ungünstig beeinflusst. Ein weiterer Empfänger wies laboranalytisch Zeichen einer HEV-Serokonversion ohne klinische Symptome auf, ein weiterer Empfänger infizierte sich nicht und die übrigen verstarben kurz nach der Transfusion an ihren Grunderkrankungen [176]. Dieses Beispiel zeigt, dass alle Abschätzungen von Risiken anhand von Modellen nicht zwingend in der Lage sind, die konkrete Risikosituation für den einzelnen Patienten darzustellen.

\subsubsection{Pathogeninaktivierung}

Grundsätzlich besteht die Möglichkeit, Thrombozytenkonzentrate mit in Deutschland zugelassenen Verfahren zur Pathogeninaktivierung zu behandeln [177]. Hierdurch können fast alle Erreger mit Nukleinsäuren inaktiviert werden und Infektionen somit vermieden werden. Die möglichen Auswirkungen dieser Verfahren auf die Qualität und Wirksamkeit der Thrombozyten sowie im Hinblick auf mögliche Nebenwirkungen der Verfahren bzw. der dabei eingesetzten Stoffe werden wissenschaftlich noch diskutiert [178]. Der AK Blut stellte in seinen Ergänzungen zum Votum 38 [179] 2008 fest, dass die Datenlage für eine abschließende Bewertung nicht ausreichend sei. Da jetzt eine Fülle von neuen Erfahrungen und Erkenntnissen zu dem Thema vorliegt, erfolgt aktuell eine (Neu-)Bewertung der Pathogeninaktivierungsverfahren für Blutkomponenten durch den AK Blut in einer separaten Stellungnahme.

\subsection{Sonstige produktbedingte relevante Risiken}

Es gibt keinen evidenten Hinweis, dass sich ATK und PTK per se im Auftreten sonstiger produktbedingter Risiken wie TRALI, FNHTR oder Immunisierung unterscheiden. Vielmehr lässt sich vermuten, dass die gefundenen Unterschiede im Wesentlichen bedingt sind/waren durch den Restgehalt an Leukozyten bzw. Plasma in den einzelnen Präparaten. Für leukozytendepletierte und in Plasma bzw. in Additivlösung resuspendierte ATK und PTK gibt es keine validen Daten, die einen Unterschied in Bezug auf das Auftreten von TRALI, FNHTR oder Immunisierungen gegen HLA-, HPA- oder Blutgruppensysteme aufzeigen [180]. 


\section{Spenderperspektive}

\subsection{Blickwinkel einzelner Spender}

Die Bereitschaft gesunder Spender zur freiwilligen, unentgeltlichen Spende von Blut- und Blutkomponenten ist die Grundlage der Transfusionsmedizin. Das Transfusionsgesetz (TFG) stellt fest: „Die spendenden Personen leisten einen wertvollen Dienst für die Gemeinschaft. Sie sind aus Gründen des Gesundheitsschutzes von den Spendeeinrichtungen besonders vertrauensvoll und verantwortungsvoll zu betreuen.“ (TFG $₫ 3$ Abs. 3). Es wird auch unter ethischen Gesichtspunkten intensiv diskutiert, wie diese generelle Verpflichtung zum besonderen Schutz der Spender auch in der konkreten Entscheidung über das Herstellungsverfahrens für TK am besten erfüllt wird [6, 181]. Die Risiken einer Vollblutspende und einer Thrombozytapherese sind zwar jeweils sehr gering. Dennoch belegen zahlreiche Studien für beide Spendearten ein Restrisiko, welches nicht völlig vernachlässigt werden kann. Die publizierten Daten zu Spenderkomplikationen bei Apherese- und Vollblutspenden zeigen eine große Streubreite der berichteten Inzidenzen und ergeben kein einheitliches Bild zum relativen Verhältnis der Risiken beider Spendearten $[6,182,183]$. Es ist jedoch zu berücksichtigen, dass das Profil der Spenderkomplikationen bei Vollblutspende und Apherese unterschiedlich ist [6]. Bei beiden Spendearten können Komplikationen durch die Venenpunktion (Nervenverletzung, Hämatom) oder systemische Reaktionen (vasovagale Reaktionen) auftreten. Bei den Apheresen können Ereignisse durch den extrakorporalen Kreislauf, die Zitratexposition oder durch die Exposition gegenüber Fremdsubstanzen (z. B. Di(2-ethylhexyl)-phtalat (DEHP)) auftreten $[184,185]$ Bei der Zitratexposition sind auch mögliche Spätwirkungen auf endrokrine Parameter und Knochenstoffwechsel zu berücksichtigen, welche trotz Kalziumsubstitution auftreten können $[186,187]$.

\subsection{Blickwinkel Spenderkollektiv}

Bei der Bewertung von Spenderkomplikationen kann zum einen der Spendevorgang selbst betrachten werden. Es kann aber auch gefragt werden, ob die Gewinnung eines bestimmten Blutproduktes der Anlass für die Spende ist, und die Spenderkomplikationen auf die hergestellten Blutprodukte bezogen werden. Betrachtet man die Spenderkomplikationen in dieser Weise und bezieht man die Spenderkomplikationen nicht auf den Spendevorgang selbst, sondern auf die aus der jeweiligen Spende hergestellten Produkte, ergibt sich ein klarer Unterschied. Bei den derzeitigen Verhältnissen von Vollblutspenden zu PTKHerstellung werden Vollblutspenden nicht gezielt zum Zwecke der alleinigen Thrombozytenherstellung entgegengenommen. Die Gewinnung von Vollblutspenden richtet sich in Deutschland derzeit allein nach dem Bedarf an Erythrozytenkonzentraten. Die Verwendung der Buffycoats für die Thrombozytenherstellung bei der Vollblutprozessierung beeinflusst den Ablauf der Spende nicht. Der Verzicht auf Herstellung von PTK aus Vollblutspenden würde das Restrisiko für Spenderkomplikationen bei Vollbutspenden somit nicht verändern. Entsprechend bedeutet die Herstellung von PTK aus Vollblutspenden kein zusätzliches Risiko für die Vollblutspender und dem Produkt PTK sind somit die Spenderrisiken nicht allein zuzuordnen.

Dagegen werden die Thrombozytapheresen ausschließlich zum Zweck der ATK-Gewinnung durchgeführt und entsprechende Risiken sind in einer produktbezogenen Betrachtung der Herstellung dieses Arzneimittels zuzuordnen $[6,181,188]$.

\section{Versorgungsaspekte}

\subsection{Aktuelle Situation in Deutschland}

Die Daten aus den Hämovigilanzmeldungen nach $₫ 21$ TFG zeigen, dass 2013 insgesamt 577.593 TK hergestellt wurden. Die Mehrzahl waren ATK (355.365, 61,5\%) (Paul-Ehrlich-Institut: Tabelle zur Meldung nach $\$ 21$ Transfusions- gesetz für das Jahr 2013, verfügbar unter [189]). Zwischen 2003 und 2012 ist die Anzahl der hergestellten TK um $60 \%$ gestiegen. 2013 war sie erstmal wieder leicht rückläufig. Der Anteil an ATK lag in diesem Zeitraum zwischen 58 und $63 \%$. Alle Organisationstypen haben die Herstellung von ATK etwa verdoppelt bei nahezu gleichen Anteilen (ca. $8 \%$ private Einrichtungen, ca. $70 \%$ Einrichtungen der StKB, ca. $21 \%$ Einrichtungen des DRK/ BRK). Die relativen Anteile an der Herstellung von PTK betrugen 2013 für die Einrichtungen des DRK/BRK $77 \%$, für die Einrichtungen der StKB 18\% und für die privaten Einrichtungen $5 \%$. Während seitens der StKB Einrichtungen die Herstellungszahlen nahezu unverändert geblieben sind, haben die DRK/BRK Einrichtungen ihre Herstellungszahlen von PTK um etwa $30 \%$ erhöht. Hinzugekommen seitens der privaten Einrichtungen ist ab 2009 eine gleichbleibende Menge an PTK.

Insgesamt 65 Blutspendeeinrichtungen haben 2011 jeweils 79 bis 939.231 Vollblutspenden abgenommen. 28 der Einrichtungen haben daraus zwischen 39 und 35.854 PTK hergestellt. Insgesamt 70 Blutspendeeinrichtungen haben 2011 TK aus 3 bis 18.980 Apheresespenden gewonnen und pro Einrichtung daraus 3 bis 24.243 ATK hergestellt.

Die Daten zum Verfall von TK zeigt - Abb. 2:

Seit Jahren verfallen mehr PTK auf der Herstellerseite als ATK. Eine konkrete Untersuchung zu den Ursachen wurde bislang nicht durchgeführt. Der Anstieg des Verfalls in den Jahren 2009-2011 ist vermutlich ein Effekt der Reduktion der Haltbarkeit von 5 auf 4 Tage. Die Logistik der TK-Bevorratung musste sich vermutlich auf diese Veränderung einstellen, die Daten für 2012 und 2013 nähern sich wieder den Verfallsraten vor 2009.

\subsection{Aktuelle Situation in Europa}

Die europäischen Staaten verfolgen unterschiedliche Strategien der Versorgung mit TK, wie aus einer Veröffentlichung des Europarats für 2010 hervorgeht. Es gab zu diesem Zeitpunkt Staaten mit überwiegender Versorgung durch ATK (Tschechische Republik, Schweiz), aber auch 


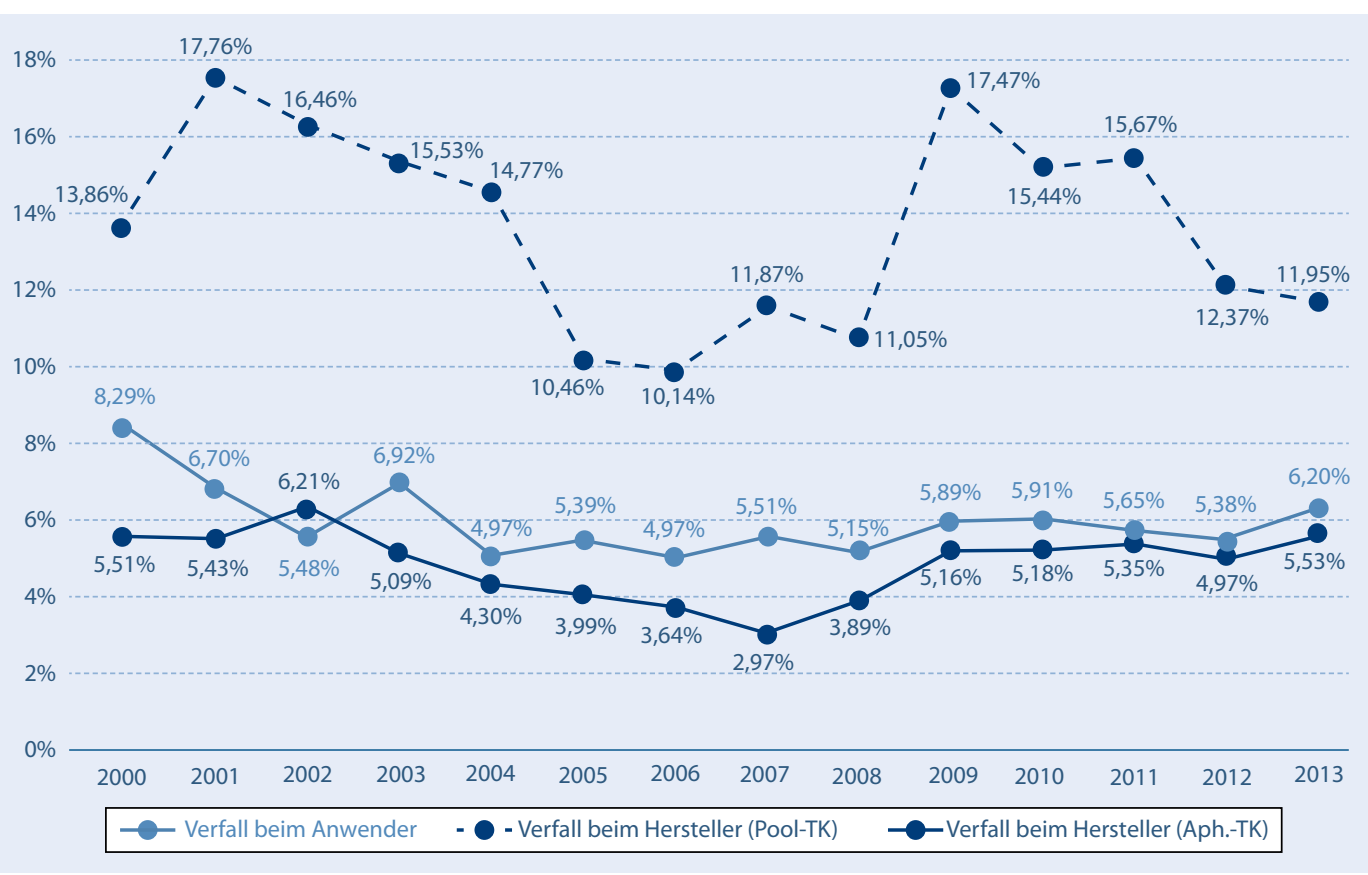

Abb. $2<$ Verfallsraten von TK beim Hersteller und Anwender (Verfallsraten bei Anwender korrigiert, siehe www.pei.de, Daten nach $\S 21 \mathrm{TFG})$

mit nahezu ausschließlicher Versorgung durch PTK (Serbien, Moldawien, Mazedonien, Finnland, Dänemark) (EDQM survey 2010, http://www.edqm.eu/en/ blood-transfusion-reports-70.html).

\subsection{Abschätzung der Möglichkeit, die Herstellung von ATK oder PTK auszudehnen}

Im Jahr 2013 trugen ATK mit einem Anteil von $61,5 \%$ sowie PTK mit einem Anteil von $38,5 \%$ zur Versorgung bei. In Kalkulationsmodellen wurde geprüft, ob eine Vollversorgung mit nur einem Präparatetyp rechnerisch möglich wäre.

\subsubsection{Abschätzung der Möglichkeit, die Herstellung von ATK auszudehnen}

Zur ATK-Gewinnung wurden im Jahr 2013 von 36.791 Spendern 185.517 Apheresespenden gemeldet, so dass je Apherese im Mittel 1,87 ATK gewonnen wurden.

Die Spender für ATK werden in den meisten Fällen bedarfsgerecht sowohl für die erforderliche Anzahl als auch mit den notwendigen $\mathrm{AB} 0$-Rh-Blutgruppen einbestellt. Insofern ist die Herstellung von ATK zielgerichteter als die Herstellung von PTK, was zu dem Unterschied im Verfall bei den Herstellern beitragen könnte (s. Abb. oben). Unter Beachtung der ak- tuell gemeldeten Daten zu ATK-Spenden könnte eine Steigerung der ATK-Herstellung bis hin zur Vollversorgung mit ATK entweder durch Erhöhung der Spendefrequenz des bestehenden Spenderstammes oder durch Erhöhung des Spenderstammes bei gleichbleibender Spendefrequenz (aktuell im Mittel ca. 5-6 Spenden/ Jahr) oder durch eine Kombination beider Möglichkeiten erreicht werden. Weiterhin bieten neuere Aphereseverfahren bei entsprechend geeigneten Spendern die Möglichkeit, aus einer Spende mehr als 2 ATK herzustellen.

Würde man nur die Spendehäufigkeit erhöhen, so müsste diese um 3 Apheresespenden/Jahr und Spender steigen auf ca. 8,3 Apheresen/Jahr. Bei einer gleichmäßigen Verteilung dieser Spenden bedeutete dies eine ATK-Spende alle 7 Wochen. Würde man unter Beibehaltung der Spendehäufigkeit den aktuellen Spenderstamm erweitern, so müssten rechnerisch ca. 24.000 neue Apherese(mehrfach)spender (ca. 60\% des aktuellen Spenderstammes) gewonnen werden.

Eine Steigerung der ATK-Herstellung hätte somit Auswirkungen auf die Spendefrequenz und/oder den Spenderstamm - beides Aspekte, welche wiederum die Risikomodellierung beeinflussen können.

\subsubsection{Abschätzung der Möglichkeit, die Herstellung von PTK auszudehnen}

In Deutschland wurden 2013 insgesamt 222.228 PTK hergestellt. Dies entspricht einem Anteil von 19\% der 4.631.290 Vollblutspenden, wenn PTK aus vier Spenden gepoolt werden. Die Einrichtungen ziehen in der Regel Vollblutspenden von Erstspendern nicht für die PTK-Herstellung heran, da von diesen zu Beginn des Herstellungsprozesses die für das blutgruppengleiche Pooling erforderliche Blutgruppeninformation noch nicht vorliegt. Bei der Spenderauswahl ist weiterhin die Medikamentenanamnese zu berücksichtigen, da bei Einnahme von u. a. Analgetika/Antipyretika, Antirheumatika, Antihypertonika, Lipidsenker oder Urikostatika eine Vollblutspende nicht für die Herstellung von PTK herangezogen werden sollte.

Bei der Auswertung der Herstellungsdaten des DRK Blutspendedienstes Baden-Württemberg-Hessen mit einer jährlichen Herstellung von ca. 70.000 PTK ergab sich in einem 18 Monatszeitraum, dass bei $42 \%$ der Vollblutspender die Spenden nicht für PTK-Herstellung verwendet wurden, $29 \%$ der Vollblutspender trugen zu einem PTK, 14\% der Vollblutspender trugen zu zwei PTK bei. Nur $15 \%$ der Vollblutspender trugen zu mehr 
als zwei Pool-TK bei. Spender, deren Vollblutspende für eine PTK-Herstellung verwendet wurde, waren signifikant älter als Spender, deren Spende nicht für PTK verwendet wurde. Dies gilt für Männer und Frauen. Bei Vollblutspenden mit Blutgruppe 0 Rh D neg., A Rh D neg., 0 Rh $\mathrm{D}$ pos. und A Rh D pos. wird ein höherer Anteil für PTK-Herstellung verwendet als in den anderen Blutgruppen. Bei Vollblutspenden mit negativem CMV-Status wird ein höherer Anteil für PTK-Herstellung verwendet als bei bekannt positivem oder ungetestetem Status. Mit zunehmender Zahl an Vollblutspenden steigt die Wahrscheinlichkeit, dass mindestens eine der Vollblutspenden für PTK verwendet wird.

Bei der Abschätzung der Möglichkeit, die Herstellung von PTK auszudehnen, müssen verschiedene Faktoren berücksichtigt werden:

- Für die Herstellung eines PTK sind vier Blutgruppen-gleiche Vollblutspenden erforderlich, d.h. die Anzahl der Vollblutspenden, die für die Herstellung eines PTK verwendet werden, muss durch vier teilbar sein („Teiler-vier-Problem“). Hierdurch können 1-12\% aller Vollblutspenden nicht mehr für die Herstellung von PTK verwendet werden, da sie kein Vielfaches von vier sind (Anteil abhängig von der Anzahl der gewonnenen Spenden).

- TK sollen gemäß Hämotherapierichtlinien [13], Kapitel 4.3.6 AB0-kompatibel, bevorzugt $\mathrm{AB} 0$-gleich transfundiert werden. Das Rhesusmerkmal D sollte berücksichtigt werden. Die Blutgruppen sind jedoch nicht gleichmäßig in der Spenderpopulation verteilt, so dass sich das „Teiler-vier-Problem" bei den selten vorkommenden Blutgruppen vor allem bei kleinen Spendeterminen nachteilig auswirken kann. Die Blutgruppen-Anforderungen für PTK im DRK-Blutspendedienst Baden-Württemberg-Hessen im Jahr 2012 waren anteilig: $0 \mathrm{RhD}+$ $33 \%, 0 \mathrm{RhD}-11 \%$, A RhD+ 32\%, A RhD- $11 \%$, B RhD+ $7 \%$, B RhD$2 \%, \mathrm{AB} \mathrm{RhD}+3 \%, \mathrm{AB} \mathrm{RhD}-1 \%$.

- Nicht alle Vollblutspenden können für die Herstellung von PTK verwendet werden, z. B. aufgrund von Medikamenteneinnahme der Spender.
Dies betraf im Jahr 2012 im DRKBlutspendedienst Baden-Württemberg-Hessen bei 767.722 Vollblutspenden 11,2\% der Spenden.

- Spenden von Erstspendern werden aufgrund der fehlenden vollständigen Blutgruppe nicht für die Herstellung von PTK herangezogen. Sie machen knapp $10 \%$ der Vollblutspenden aus [125].

Bei der Abschätzung der Herstellungsmöglichkeiten können anhand der oben aufgeführten grundsätzlichen Erwägungen Kalkulationen durchgeführt werden. Anhand der Hämovigilanzdaten des PEI für Spendeeinrichtungen mit mehr als 20.000 Vollblutspenden/Jahr wurden folgende Annahmen gemacht:

- Vollblutspendenzahl der Einrichtungen p.a. berücksichtigt bei Berechnung des Verlustes durch „Teiler-vier-Problem“ (angepasst für die Größenklassen 20.000-50.000, 50.000-100.000, 100.000-250.000 und $>250.000$ VB-Spendern p.a.)

- Worst-Case Szenario für „Teiler-vierProblem“ (Annahme des maximal möglichen relativen Verlustes).

- Verteilung auf 250 Spende-/Produktionstage pro Jahr

- Blutgruppenverteilung in der Spenderpopulation

- Blutgruppenverteilung bei der Abgabe von PTK.

- Zahlen für Vollblutspenden und freigegebene EK: PEI, TFG- $\$ 21$-Bericht 2011

- Zahlen für Bedarf an TK: PEI, TFG$\S 21$-Bericht 2011

Diese Kalkulation kommt zu dem Ergebnis, dass die Herstellung der in Deutschland erforderlichen Anzahl von PTK aus Vollblutspenden grundsätzlich möglich wäre, solange es keine starken Schwankungen im Spendenaufkommen gibt. Bei streng Blutgruppen-identischer Versorgung ist eine Versorgung mit PTK für $0 \mathrm{RhD}+, \mathrm{A} \mathrm{RhD}+, \mathrm{B}$ und $\mathrm{AB}$ möglich, aber die eigenständige Versorgung mit 0 RhD-, A RhD- PTK ist in Einrichtungen mit weniger als 50.000 Spenden nicht möglich. Einrichtungen dieser Größe finden sich vor allem patientennah an den Kliniken. Auch universi- täre Spendeeinrichtungen mit einem hohen TK-Bedarf für ihr eigenes Klinikum haben häufig weniger als 50.000 Vollblutspenden/Jahr. Diese Einrichtungen müssten für die Thrombozytenversorgung auf externe TK aus größeren Spendeeinrichtungen zurückgreifen.

Die oben dargestellten Modelle zeigen, dass aus der Perspektive des Herstellungspotentials eine Verschiebung des aktuellen ATK:PTK-Verhältnisses sowohl zugunsten der ATK als auch zugunsten der PTK grundsätzlich möglich wäre. Die Modelle machen deutlich, von welchen Parametern eine weitgehende Versorgung durch jeweils einen Präparatetyp abhängig wäre. Im Modell der PTKHerstellung sind wesentliche Einflussfaktoren eine Veränderung der Anzahl der verfügbaren Vollblutspenden sowie zeitliche Fluktuationen im Vollblutspendenaufkommen.

Sowohl für eine Steigerung der ATK als auch der PTK-Herstellung wären Anpassungen der Herstellungsressourcen erforderlich. Weiterhin ist zu berücksichtigen, dass eine wesentliche Veränderung des aktuellen Herstellungsverhältnisses auch Auswirkungen auf die Versorgungsstruktur haben kann. Neben vorhersehbaren und entsprechend gut planbaren TK-Transfusionen besteht vielfach auch kurzfristiger, nicht vorsehbarer Bedarf an Thrombozytenkonzentraten. Dies betrifft am meisten die Einrichtungen der Maximalversorgung, wie Universitätskliniken.

In einer Gesamtbetrachtung von Versorgungssicherheit, Versorgungsqualität, Versorgungsstrukturen, Herstellungspotential und Spenderperspektive ist eine duale Versorgungsstruktur mit Verfügbarkeit von sowohl ATK als auch PTK erforderlich. Dies sichert auch, dass Expertise und Ressourcen für die Herstellung beider Präparatetypen erhalten bleiben. Insbesondere für die Versorgung von immunisierten Patienten ist eine ausreichende Anzahl von kliniknahen Spendeeinrichtungen, die regelmäßig TK-Apheresen durchführen, zwingend erforderlich. Typisierte Präparate lassen sich nur von einem aktiven getesteten AphereseSpenderstamm gewinnen. 
Tab. 4 Übersicht über die Zusatzentgelte in Euro gemäß Entgeltkatalog des Instituts für das Entgeltsystem im Krankenhaus (InEK) für 2015 (ZE 146 und ZE 147) für Empfänger über 14 Jahre

\begin{tabular}{rrrr}
\hline Anzahl TK & ATK & PTK & Differenz \\
\hline 1 & 0 & 0 & 0 \\
\hline 2 & 746,83 & 0 & 746,83 \\
\hline 3 & 1120,25 & 0 & 1120,25 \\
\hline 4 & 1493,66 & 1006,40 & 487,26 \\
\hline 5 & 1865,08 & 1258,00 & 607,08 \\
\hline $6-8$ & 2384,60 & 1588,04 & 796,56 \\
\hline
\end{tabular}

\subsection{Erstattungsaspekte}

Der Vergleich von PTK und ATK wird primär anhand der Aspekte Qualität, Sicherheit und Wirksamkeit für die Patienten sowie Sicherheit für die Spender geführt. Für eine umfassende Darstellung der Gesamtsituation ist allerdings auch wichtig, die derzeitige Erstattungspraxis für ATK und PTK zu betrachten. Aufgrund unterschiedlicher Herstellungskosten sowie der Systematik und Weiterentwicklung im DRG-System werden diese beiden Produkttypen unterschiedlich vergütet. Weiterhin ist zu berücksichtigen, dass PTK von vielen Einrichtungen der Krankenversorgung nicht selbst hergestellt, sondern von Blutspendediensten extern bezogen werden. Für die ATK ist der Anteil der Eigenherstellung in den Einrichtungen der Krankenversorgung höher. Beide Präparatetypen führen zu Zusatzentgelten, wenn bei der Behandlung eines Falls (stationärer Aufenthalt) die Zahl der transfundierten Präparate eine festgelegte Schwelle überschreitet. Die Zusatzentgelte werden jährlich angepasst und im G-DRG-Fallpauschalenkatalog veröffentlich (www.g-drg.de). Der Fallpauschalenkatalog 2015 sieht für ATK das Zusatzentgelt ZE 147 ab dem 2. ATK sowie für PTK das Zusatzentgelt ZE 146 ab dem 4. PTK vor (Ausnahme: bei Empfängern unter 15 Jahren gibt es bei ATK ein Zusatzentgelt schon ab dem ersten und bei PTK ab dem zweiten transfundierten Präparat). Die Zusatzentgelte für ATK und PTK unterscheiden sich in ihrer Höhe und sind nach Zahl der transfundierten Präparate gestaffelt (so genannte „sprungfixe Vergütungen“). Die Anzahl der Präparate, welche jeweils transfundiert werden müssen, um eine Vergütung zu erreichen, unterscheiden sich zwischen den Zusatzentgelten ZE 146 und ZE 147.
Bei einem erwachsenen Empfänger führt die Transfusion von 2 ATK während eines stationären Aufenthalts zu einem Zusatzentgelt von $746,83 €$ während die Transfusion von 2 PTK kein Zusatzentgelt auslöst. Einen Überblick der Zusatzentgelte für Patienten > 14 Jahre bietet $\bullet$ Tab. 4.

Bei Empfängern, welche unter 15 Jahre sind, löst die Transfusion von einem ATK ein ZE in Höhe von 373,42 € aus, die Transfusion von 1 PTK $0 €$, bei Transfusion von 2 PTK führt zu einem Erlös von $503,20 €$, die Transfusion von 3 PTK zu einem Erlös von 754,80 €.

Die historisch gewachsene unterschiedliche Vergütung von ATK und PTK aufgrund unterschiedlicher Herstellungskosten führt jetzt zu der Situation, dass ATK z. T. nur unter Vorbehalt erstattet werden. Dies resultiert in einer starken Verunsicherung und Gefährdung der bestehenden Versorgungsstruktur. Die unterschiedlichen Schwellen und unterschiedlichen Staffeln für die Vergütung sind ungünstig, da es sich jeweils um eine Gabe einer therapeutischen Einheit mit im Mittelwert ca. $3 \times 10^{11}$ Thrombozyten handelt und die sprungfixen Vergütung Fehlanreize für die Transfusion setzt.

Eine Veränderung der aktuellen Versorgungsstruktur würde auf die Risikobewertung beider Produkte und auf die Struktur der Spendeeinrichtungen insgesamt Auswirkungen haben. Eine gesicherte Versorgung könnte bei Konzentration auf eine Herstellungsart gefährdet sein.

Die HLA- und/oder HPA-ausgewählten Thrombozytenpräparate werden im DRG-System als „patientenbezogene Thrombozytenkonzentrate " getrennt erfasst und mit einem eigenständigen $\mathrm{Zu}$ satzentgelt vergütet.

\subsection{Auswirkungen einer Veränderung der Versorgungsstruktur}

Risikomodellierung: Da die epidemiologischen Daten zeigen, dass sich Infektionen nicht gleichmäßig in der Spenderpopulation verteilen, wird eine Änderung der Spenderpopulation mit hoher Wahrscheinlichkeit für die bekannten Infektionen auch eine Veränderung der Inzidenz unter Spendern und damit auch zur Veränderung des Restrisikos führen. So zeigte sich, dass z. B. HIV-Infektionen signifikant häufiger bei spendenden Männern als bei Frauen auftreten. Auch gibt es seit Jahren gleichbleibende Altersunterschiede bei den inzidenten HIV-, HBV-, HCVund Syphilisinfektionen [125, 160, 161]. Auch die Regionalität der Spender (durch Einzugsbereich der Spendeeinrichtungen geschätzt) hat Auswirkungen auf die Infektionshäufigkeiten [163].

Dadurch, dass die Häufigkeit der Spenden auch Auswirkungen auf die Wahrscheinlichkeit einer Fensterphasenspende hat $[162,163]$, würde sich auch die Veränderung der minimalen Spenderintervalle für die bekannten Infektionen, insbesondere HBV-Infektionen, risikominimierend auswirken.

Versorgungsstruktur: Bei einer Umstellung auf eine überwiegende Versorgung mit PTK ist zu beachten, dass kleine kliniknahe Spendeeinrichtungen an Universitätsklinika oder Krankenhäusern der Maximalversorgung, welche überwiegend ATK im Rahmen ihrer klinischen Hämotherapie einsetzen, zu wenig Vollblutspenden gewinnen, um durch eigenhergestellte PTK die Versorgung in gleicher Weise wie mit ATK sicherzustellen. Diese Einrichtungen der Krankenversorgung müssten auf PTK anderer Spendeeinrichtungen zurückgreifen, was angesichts der kurzen Lagerungsdauer und der Funktionseinschränkung der TK bei nicht agitiertem Transport zu Problemen bei der Patientenversorgung und zu einem erhöhten Verfall führen könnte.

Eine Umstellung auf eine überwiegende Versorgung mit PTK führt dazu, dass Patienten mit HLA- oder HPA-Antikörpern schlecht oder gar nicht mit typisierten TK versorgt werden können und sie 
möglicherweise lebensbedrohliche Blutungskomplikationen erleiden könnten. $\mathrm{Da}$ auch ATK-Spender bei Abruf nicht immer für die Spende geeignet sind (z. B. wegen akuter Medikamenteneinnahme, Infekten oder Reisen), muss der Pool der verfügbaren aktiven Spender groß genug sein, um die Versorgung mit typisierten TK zu sichern. Zusätzlich müssen genügend Zentren Expertise und die erforderlichen Geräte für den Bereich Thrombozytapherese aufweisen. Eine Versorgung dieser Patienten muss schon aufgrund der kurzen Lagerungsdauer der TK kliniknah erfolgen.

Zusätzlich ist zu beachten, dass die genannten kliniknahen, häufig universitären Einrichtungen möglicherweise dann in ihrem Erhalt gefährdet wären, wenn die weitgehend klinikeigene TK-Versorgung nicht mehr gewährleistet werden könnte. Das würde vermutlich erhebliche Auswirkungen auf die Struktur des gesamten Blutspendewesens und die universitären Ausbildungsstätten für Transfusionsmedizin in Deutschland haben. Dadurch, dass für eine flächendeckende sichere Versorgung mit Blutgruppengleichen PTK bevorzugt große Spendeeinrichtungen die Herstellung übernehmen müssten, besteht die Möglichkeit, dass die Blutversorgung insgesamt durch die großen Anbieter übernommen würde und das bislang praktizierte 3-SäulenSystem der Blutversorgung in Deutschland aufgegeben wird.

\section{Literatur}

1. http://www.g-drg.de/cms/G-DRG-System_2014/ Fallpauschalen-Katalog/Fallpauschalen-Katalog_2014.Zugegriffen: 15. Mai 2015

2. http://www.dgti.de/docs/doclink/10590/DGTI_ Stellungnahme_TK_20111219.pdf. Zugegriffen: 15. Mai 2015

3. Stellungnahme der StKB zur Therapie mit unterschiedlichen Thrombozytenkonzentraten vom 27.12.2011. http://www.stkb.de/verband_publikationen.html. Zugegriffen: 15. Mai 2015

4. Zimmermann R, Bender AW (2011) Pool- versus Apherese-Thrombozytenkonzentrate. Wissenschaftliches Gutachten zur Wertigkeit der Präparate und den rechtlichen Implikationen. http:// www.bdtev.de/wp-content/uploads/2011/05/ BDT-Gutachten-ATK-vs-PTK-20111007-Zimmermann-Bender.pdf. Zugegriffen: 15. Mai 2015
5. Bundesärztekammer (2010) Richtlinien zur Gewinnung von Blut und Blutbestandteilen und zur Anwendung von Blutprodukten (Hämotherapie): Aufgestellt gemäß Transfusionsgesetz von der Bundesärztekammer im Einvernehmen mit dem Paul-Ehrlich-Institut/Gesamtnovelle 2005, mit Richtlinienanpassung 2010. Deutscher Ärzte-Verlag, Köln

6. Schrezenmeier H, Seifried E (2010) Buffy-coat-derived pooled platelet concentrates and apheresis platelet concentrates: which product type should be preferred? Vox Sang 99:1-15

7. Armstrong B, Hardwick J, Raman L, Smart E, Wilkinson RW (2008) Introduction to blood transfusion technology. Vox Sang ISBT 3:165-167

8. Slichter SJ (2007) Platelet transfusion therapy. Hematol Oncol Clin North Am 21:697-729

9. Murphy S, Gardner FH (1969) The effect of temperature on platelet viability. Vox Sang 17:22

10. Murphy S, Gardner FH (1969) Effect of storage temperature on maintenance of platelet viability-deleterious effect of refrigerated storage. $\mathrm{N}$ Engl J Med 280:1094-1098

11. Murphy S, Gardner FH (1969) Platelet preservation: effect of storage temperature on maintenance of platelet viability - deleterious effect of refrigerated storage. N Engl J Med 280:1094-1098

12. AABB (2011) Standards for blood banks and transfusion services

13. Council of Europe (2011) Guide to the preparation, use and quality assurance of blood components (CD-P-TS) ECoBT, 16. Aufl. Council of Europe Publishing, Strasbourg

14. Dijkstra-Tiekstra MJ, Kuipers W, Setroikromo AC, Wildt-Eggen D (2008) Overnight or fresh buffy coat-derived platelet concentrates prepared with various platelet pooling systems. Transfusion 48:723-730

15. Dijkstra-Tiekstra $M$, van der Meer $P$, Cardigan $R$, Devine D, Prowse C et al (2011) Platelet concentrates from fresh or overnight-stored blood, an international study. Transfusion 51:38S-44S

16. Sandgren P, Callaert M, Shanwell A, Gulliksson $\mathrm{H}$ (2008) Storage of platelet concentrates from pooled buffy coats made of fresh and overnight-stored whole blood processed on the novel Atreus $2 \mathrm{C}+$ system: in vitro study. Transfusion 48:688-696

17. Pérez-Pujol S, Lozano M, Perea D, Mazzara R, Ordinas A et al (2004) Effect of holding buffy coats 4 or 18 hours before preparing pooled filtered PLT concentrates in plasma. Transfusion 44:202209

18. Thibault L, Beauséjour A, De Grandmont MJ, Lemieux R, Leblanc JF (2006) Characterization of blood components prepared from whole-blood donations after a 24-hour hold with the plateletrich plasma method. Transfusion 46:1292-1299

19. Sanz C, Pereira A, Faundez A, Ordinas A (1997) Prolonged holding of whole blood at 22 degrees $C$ does not increase activation in platelet concentrates. Vox San 72:225-228

20. van der Meer PF, Cancelas JA, Vassallo RR, Rugg $\mathrm{N}$, Einarson $\mathrm{M}$ et al (2011) Evaluation of the overnight hold of whole blood at room temperature, before component processing: platelets (PLTs) from PLT-rich plasma. Transfusion 51:45S-49S

21. van der Meer PF, de Korte D (2011) Active cooling of whole blood to room temperature improves blood component quality. Transfusion 51:357362
22. Pietersz RN, Reesink HW, Pauw W, Dekker WJ, Buisman L (1992) Prevention of Yersinia enterocolitica growth in red-blood-cell concentrates. Lancet 340:755-756

23. Sanz C, Pereira A, Vila J, Faundez Al, Gomez J et al (1997) Growth of bacteria in platelet concentrates obtained from whole blood stored for 16 hours at 22 degrees $C$ before component preparation. Transfusion 37:251-254

24. Hogman C, Gong J, Eriksson L, Hambraeus A, Johansson C (1991) White cells protect donor blood against bacterial contamination. Transfusion 31:620-626

25. Gong J, Hogman C, Hambraeus A, Johansson C, Eriksson L (1993) Transfusion-associated Serratia marcescens infection: studies of the mechanism of action. Transfusion 33:802-808

26. Mohr H, Bayer A, Gravemann U, Müller TH (2006) Elimination and multiplication of bacteria during preparation and storage of buffy coat-derived platelet concentrates. Transfusion 46:949-955

27. Benjamin RJ, Kline L, Dy BA, Kennedy J, Pisciotto $P$ et al (2008) Bacterial contamination of whole blood-derived platelets: the introduction of sample diversion and prestorage pooling with culture testing in the American Red Cross. Transfusion 48:2348-2355

28. Wilsher C, Garwood M, Sutherland J, Turner C, Cardigan R (2008) The effect of storing whole blood at $22^{\circ}$ for up to 24 hours with and without rapid cooling on the quality of red cell concentrates and fresh-frozen plasma. Transfusion 48:2338-2347

29. Beutler $E$, Wood $L$ (1969) The in vivo regeneration of red cell 2,3 diphosphoglyceric acid (DPG) after transfusion of stored blood. J Lab Clin Med 74:300

30. Heaton A, Keegan T, Holme S (1989) In vivo regeneration of red cell 2,3-diphosphoglycerate following transfusion of DPG-depleted AS-1, AS-3 and CPDA-1 red cells. Br J Haematol 71:131-136

31. Valeri CR, Hirsch NM (1969) Restoration in vivo of erythrocyte adenosine triphosphate, 2,3-diphosphoglycerate, potassium ion, and sodium ion concentrations following the transfusion of acidcitrate-dextrose-stored human red blood cells. J Lab Clin Med 73:722-733

32. Llohn AH, Vetlesen A, Fagerhol MK, KjeldsenKragh J (2005) The effect of pre-storage cooling on 2,3-DPG levels in red cells stored in SAG-M. Transfus Apher Sci 33:113-118

33. Reikvam H, Prowse C, Roddie H, Heddle N, Hervig $T$ (2010) A pilot study of the possibility and the feasibility of haemoglobin dosing with red blood cells transfusion. Vox Sang 99:71-76

34. Chabanel A, Carrat F, Begue S, Masse M, Perrault M et al. (2008) Quality of leucoreduced red blood cell concentrates: 5 years of follow-up in France. Vox Sang 94:41-47

35. Schrezenmeier H, Seifried E (2010) Response to Zimmermann et al. Vox San 99:297

36. Zimmermann R, Blasczyk R, Zingsem J, Eckstein $R$, Heuft $H$ (2010) Disparate risks and effects of pooled whole blood-derived vs. apheresis platelet production require an integral view on the blood supply. Vox Sang 99:295-296

37. Zimmermann R, Weiss DR, Zingsem J, Ringwald J, Eckstein R (2012) Pooled platelet concentrates and the quality of the red blood cell supply. Clin Lab 58:1-6

38. Vamvakas EC, Hitzler WE (2013) Consistency and proportionality in policy decision-making in blood safety: the case for an all-apheresis platelet supply in Germany. Clin Lab 59:1-22 
39. Snyder EL, Whitley P, Kingsbury T, Miripol J, Tormey CA (2010) In vitro and in vivo evaluation of a whole blood platelet-sparing leukoreduction filtration system. Transfusion 50:2145-2151

40. Gulliksson H, van der Meer PF (2009) Storage of whole blood overnight in different blood bags preceding preparation of blood components: in vitro effects on red blood cells. Blood Transfus 7:210

41. Picker SM, Radojska SM, Gathof BS (2006) Prospective comparison of high-dose plateletpheresis with the latest apheresis systems on the same donors. Transfusion 46:1601-1608

42. Heuft HG, Moog R, Fischer EG, Zingsem J, German et al (2013) Donor safety in triple plateletpheresis: results from the German and Austrian Plateletpheresis Study Group multicenter trial. Transfusion 53:211-220

43. Ringwald J, Zingsem J, Zimmermann R, Strasser $\mathrm{E}$, Antoon M et al(2003) First comparison of productivity and citrate donor load between the Tri$\mathrm{ma}^{\oplus}$ version 4 (dual-stage filler) and the Trima Accel $^{\otimes}$ (single-stage filler) in the same donors. Vox Sang 85:267-275

44. Fontana S, Mordasini L, Keller P, Taleghani BM (2006) Prospective, paired crossover comparison of multiple, single-needle plateletpheresis procedures with the Amicus and Trima Accel cell separators. Transfusion 46:2004-2010

45. Vassallo RR, Wahab F, Giordano K, Murphy S (2004) Improving technology for collecting platelets by apheresis: five-year experience in one blood center. Transfus Med Rev 18:257-266

46. Richa E, Krueger P, Burgstaler EA, Bryant SC, Winters JL (2008) The effect of double-and tripleapheresis platelet product donation on apheresis donor platelet and white blood cell counts. Transfusion 48:1325-1332

47. Zhang JG, Carter CJ, Culibrk B, Devine DV, Levin E et al (2008) Buffy-coat platelet variables and metabolism during storage in additive solutions or plasma. Transfusion 48:847-856

48. Cardigan R, Sutherland J, Garwood M, Bashir S, Turner C et al (2008) In vitro function of buffy coat-derived platelet concentrates stored for 9 days in CompoSol, PASIl or $100 \%$ plasma in three different storage bags. Vox Sang 94:103-112

49. Ringwald J, Haager B, Krex D, Zimmermann R, Strasser E et al (2006) Impact of different hold time before addition of platelet additive solution on the in vitro quality of apheresis platelets. Transfusion 46:942-948

50. Ringwald J, Zimmermann R, Eckstein R (2006) The new generation of platelet additive solution for storage at $22^{\circ} \mathrm{C}$ : development and current experience. Transfus Med Rev 20:158-164

51. Azuma H, Hirayama J, Akino M, Ikeda H (2011) Platelet additive solution-electrolytes. Transfus Apher Sci 44:277-281

52. Alhumaidan H, Sweeney J (2012) Current status of additive solutions for platelets. J Clin Apher 27:93-98

53. Greco CA, Zhang JG, Kalab M, Yi QL, Ramirez-Arcos SM et al (2010) Effect of platelet additive solution on bacterial dynamics and their influence on platelet quality in stored platelet concentrates. Transfusion 50:2344-2352

54. Dumont LJ, Wood TA, Housman M, Herschel L, Brantigan $B$ et al (2011) Bacterial growth kinetics in ACD-A apheresis platelets: comparison of plasma and PAS III storage. Transfusion 51:10791085
55. Heddle NM, Klama L, Singer J, Richards C, Fedak $P$ et al (1994) The role of the plasma from platelet concentrates in transfusion reactions. N Engl J Med 331:625-628

56. Heddle NM, Klama L, Meyer R, Walker I, Boshkov L et al (1999) A randomized controlled trial comparing plasma removal with white cell reduction to prevent reactions to platelets. Transfusion 39:231-238

57. Heddle NM, Blajchman MA, Meyer RM, Lipton $\mathrm{JH}$, Walker IR et al (2002) A randomized controlled trial comparing the frequency of acute reactions to plasma-removed platelets and prestorage WBC-reduced platelets. Transfusion 42:556566

58. Paglino JC, Pomper GJ, Fisch GS, Champion MH, Snyder EL (2004) Reduction of febrile but not allergic reactions to $\mathrm{RBC}$ s and platelets after conversion to universal prestorage leukoreduction. Transfusion 44:16-24

59. Wildt-Eggen D, Gulliksson $H$ (2003) In vivo and in vitro comparison of platelets stored in either synthetic media or plasma. Vox Sang 84:256-264

60. Kerkhoffs J-LH, Eikenboom JC, Schipperus MS van Wordragen-Vlaswinkel RJ, Brand $\mathrm{R}$ et al (2006) A multicenter randomized study of the efficacy of transfusions with platelets stored in platelet additive solution II versus plasma. Blood 108:3210-3215

61. Hirayama J, Azuma H, Fujihara M, Akino M, Homma C et al (2008) Storage of platelets in 30 percent plasma and 70 percent $\mathrm{M}$-sol additive solution. Transfusion 48:567-568

62. Azuma H, Hirayama J, Akino M, Miura R, Kiyama $Y$ et al (2009) Reduction in adverse reactions to platelets by the removal of plasma supernatant and resuspension in a new additive solution (Msol). Transfusion 49:214-218

63. Wildt-Eggen D, Nauta S, Schrijver J, van Marwijk Kooy M, Bins M et al (2000) Reactions and platelet increments after transfusion of platelet concentrates in plasma or an additive solution: a prospective, randomized study. Transfusion 40:398403

64. Ringwald J, Walz S, Zimmermann R, Zingsem J, Strasser E et al (2005) Hyperconcentrated platelets stored in additive solution: aspects on productivity and in vitro quality. Vox Sang 89:11-18

65. Perseghin P (2011) High concentration plasmareduced plateletapheresis concentrates. Transfus Apher Sci 44:273-276

66. Radwanski K, Wagner SJ, Skripchenko A, Min K (2012) In vitro variables of apheresis platelets are stably maintained for 7 days with $5 \%$ residual plasma in a glucose and bicarbonate salt solution, PAS-5. Transfusion 52:188-194

67. Johnson L, Winter KM, Hartkopf-Theis T, Reid S, Kwok M et al (2012) Evaluation of the automated collection and extended storage of apheresis platelets in additive solution. Transfusion 52:503509

68. Moroff G, Kurtz J, Seetharaman S, Skripchenko A, Awatefe $\mathrm{H}$ et al (2012) Comparative in vitro evaluation of apheresis platelets stored with $100 \%$ plasma or $65 \%$ platelet additive solution III/35\% plasma and including periods without agitation under simulated shipping conditions. Transfusion 52:834-843

69. Ringwald J, Tully S, Geier C, Hauck B, Weiss D et al (2012) Effects of immediate or delayed addition of platelet additive solution on the in vitro quality of apheresis platelets. Transfusion 52:12371244
70. http://www.pei.de/DE/infos/pu/zulassung-humanarzneimittel/verfahren/blut-blutkomponenten/muster/blutkomponenten-gebrauchsinformation-fachinformation-tabelle.html. Zugegriffen: 15. Mai 2015

71. Koreth R, Weinert C, Weisdorf DJ, Key NS (2004) Measurement of bleeding severity: a critical review. Transfusion 44:605-617

72. Estcourt LJ, Pinchon D, Symington E, Kelly AM, Doree $C$ et al (2014) Does bleeding affect patient-reported outcome measures in patients with myelodysplasia or hematologic malignancies: a systematic review. Transfusion 54:1166-1179

73. Webert KE, Arnold DM, Lui Y, Carruthers J, Arnold E et al (2012) A new tool to assess bleeding severity in patients with chemotherapy-induced thrombocytopenia. Transfusion 52:2466-2474. (quiz 2465)

74. Friedmann AM, Sengul $H$, Lehmann $H$, Schwartz C, Goodman S (2002) Do basic laboratory tests or clinical observations predict bleeding in thrombocytopenic oncology patients? A reevaluation of prophylactic platelet transfusions. Transfus Med Rev 16:34-45

75. Slichter SJ (2004) Relationship between platelet count and bleeding risk in thrombocytopenic patients. Transfus Med Rev 18:153-167

76. Li N, Williams L, Zhou Z, Wu Y (2014) Incidence of acute transfusion reactions to platelets in hospitalized pediatric patients based on the US hemovigilance reporting system. Transfusion 54:16661672

77. Reesink HW, Lee J, Keller A, Dennington P, Pink J et al (2012) Measures to prevent transfusion-related acute lung injury (TRALI). Vox Sang 103:231259

78. Bux J (2005) Transfusion-related acute lung injury (TRALI): a serious adverse event of blood transfusion. Vox Sang 89:1-10

79. Blumberg N, Heal JM, Phillips GL, Phipps RP (2012) Platelets-to transfuse or not to transfuse. Lancet 380:1287-1289

80. Blumberg N, Heal JM, Liesveld JL, Phillips GL, Rowe JM (2008) Platelet transfusion and survival in adults with acute leukemia. Leukemia 22:631635

81. Bundesärztekammer (2009) Querschnitts-Leitlinien (BÄK) zur Therapie mit Blutkomponenten und Plasmaderivaten (4. überarbeitete Auflage 2008). Deutscher Ärzte-Verlag, Köln

82. Schiffer CA, Anderson KC, Bennett CL, Bernstein $S$, Elting LS et al (2001) Platelet transfusion for patients with cancer: clinical practice guidelines of the American Society of Clinical Oncology. J Clin Oncol 19:1519-1538

83. Sagmeister M, Oec L, Gmur J (1999) A restrictive platelet transfusion policy allowing long-term support of outpatients with severe aplastic anemia. Blood 93:3124-3126

84. Stanworth SJ, Hyde C, Heddle N, Rebulla P, Brunskill S et al (2004) Prophylactic platelet transfusion for haemorrhage after chemotherapy and stem cell transplantation. Cochrane Database Syst Rev 4:Cd004269

85. Patten E (1992) Controversies in transfusion medicine. Prophylactic platelet transfusion revisited after 25 years: con. Transfusion 32:381-385

86. Schiffer CA (1992) Prophylactic platelet transfusion. Transfusion 32:295-298

87. Stanworth SJ, Hyde C, Brunskill S, Murphy MF (2005) Platelet transfusion prophylaxis for patients with haematological malignancies: where to now? Br J Haematol 131:588-595 
88. Blajchman MA, Slichter SJ, Heddle NM, Murphy MF (2008) New strategies for the optimal use of platelet transfusions. Hematology Am Soc Hematol Educ Program 2008:198-204

89. Wandt $H$, Schaefer-Eckart $K$, Wendelin K, Pilz B, Wilhelm M et al (2012) Therapeutic platelet transfusion versus routine prophylactic transfusion in patients with haematological malignancies: an open-label, multicentre, randomised study. Lancet 380:1309-1316

90. Estcourt LJ, Stanworth SJ, Harrison P, Powter G, McClure M et al (2014) Prospective observational cohort study of the association between thromboelastometry, coagulation and platelet parameters and bleeding in patients with haematological malignancies- the ATHENA study. Br J Haematol 166:581-591

91. Stanworth SJ, Estcourt LJ, Powter G, Kahan BC, Dyer C et al (2013) A no-prophylaxis platelettransfusion strategy for hematologic cancers. N Engl J Med 368:1771-1780

92. Wandt $H$, Frank M, Schaefer-Eckart K, Wilhelm M (2005) Routine prophylactic platelet transfusions are not necessary in patients with acute myeloid leukemia-a therapeutic transfusion strategy is safe and cost effective. Blood (ASH Annual Meeting Abstracts) 106: Abstract 428

93. Wandt H, Schaefer-Eckart K, Frank M, Birkmann J, Wilhelm M (2006) A therapeutic platelet transfusion strategy is safe and feasible in patients after autologous peripheral blood stem cell transplantation. Bone Marrow Transplant 37:387-392

94. Estcourt L, Stanworth S, Doree C, Hopewell S, Murphy MF et al (2012) Prophylactic platelet transfusion for prevention of bleeding in patients with haematological disorders after chemotherapy and stem cell transplantation. Cochrane Database Syst Rev 5:CD004269

95. Schiffer CA (2013) Prophylactic platelet transfusion is frequently not necessary. Nat Rev Clin Oncol 10:431-432

96. Slichter SJ, Kaufman RM, Assmann SF, McCullough J, Triulzi DJ et al (2010) Dose of prophylactic platelet transfusions and prevention of hemorrhage. N Engl J Med 362:600-613

97. Heim D, Passweg J, Gregor M, Buser A, Theocharides A et al (2008) Patient and product factors affecting platelet transfusion results. Transfusion 48:681-687

98. Estcourt $L J$ (2014) Why has demand for platelet components increased? A review. Transfus Med 24:260-268

99. Holme S, Sweeney JD, Sawyer S, Elfath MD (1997) The expression of p-selectin during collection, processing, and storage of platelet concentrates: relationship to loss of in vivo viability. Transfusion 37:12-17

100. Holme S, Moroff G, Murphy S (1998) A multi-laboratory evaluation of in vitro platelet assays: the tests for extent of shape change and response to hypotonic shock. Biomedical Excellence for Safer Transfusion Working Party of the International Society of Blood Transfusion. Transfusion 38:3140

101. Dumont LJ, Beddard R, Whitley $P$, Johnson $A$, McNeil D et al (2002) Autologous transfusion recovery of WBC-reduced high-concentration platelet concentrates. Transfusion 42:1333-1339

102. AuBuchon JP, Taylor H, Holme S, Nelson E (2005) In vitro and in vivo evaluation of leukoreduced platelets stored for 7 days in CLX containers. Transfusion 45:1356-1361
103. Ranucci M, Baryshnikova E, Soro G, Ballotta A, De Benedetti $D$ et al (2011) Multiple electrode whole-blood aggregometry and bleeding in cardiac surgery patients receiving thienopyridines. Ann Thorac Surg 91:123-129

104. Anderson NA, Gray S, Copplestone JA, Chan DC, Hamon M et al (1997) A prospective randomized study of three types of platelet concentrates in patients with haematological malignancy: corrected platelet count increments and frequency of nonhaemolytic febrile transfusion reactions. Transfus Med 7:33-39

105. Kluter $H$, Dorges $L$, Maass $E$, Wagner T, Bartels $H$ et al (1996) In-vivo evaluation of random donor platelet concentrates from pooled buffy coats. Ann Hematol 73:85-89

106. Gmur J, von Felten A, Osterwalder B, Honegger $H$, Hormann A et al (1983) Delayed alloimmunization using random single donor platelet transfusions: a prospective study in thrombocytopenic patients with acute leukemia. Blood 62:473479

107. The Trial to reduce alloimmization to platelets study group (1997) Leukocyte reduction and ultraviolet B irradiation of platelets to prevent alloimmunization and refractoriness to platelet transfusions. N Engl J Med 337:1861-1869

108. Strindberg J, Berlin G (1996) Transfusion of platelet concentrates-clinical evaluation of two preparations. Eur J Haematol 57:307-311

109. Gurkan E, Patah PA, Saliba RM, Ramos CA, Anderson BS et al (2007) Efficacy of prophylactic transfusions using single donor apheresis platelets versus pooled platelet concentrates in $\mathrm{AML} /$ MDS patients receiving allogeneic hematopoietic stem cell transplantation. Bone Marrow Transplant 40:461-464

110. Eriksson L, Kristensen J, Olsson K, Bring J, Hog man CF (1996) Evaluation of platelet function using the in vitro bleeding time and corrected count increment of transfused platelets. Comparison between platelet concentrates derived from pooled buffy coates and apheresis. Vox Sang 70:69-75

111. Akkok CA, Brinch L, Lauritzsen GF, Solheim BG Kjeldsen-Kragh J (2007) Clinical effect of buffycoat vs. apheresis platelet concentrates in patients with severe thrombocytopenia after intensive chemotherapy. Vox Sang 93:42-48

112. Heddle NM, Arnold DM, Boye D, Webert KE, Resz l et al (2008) Comparing the efficacy and safety of apheresis and whole blood-derived platelet transfusions: a systematic review. Transfusion 48:1447-1458

113. Triulzi DJ, Assmann SF, Strauss RG, Ness PM, Hess JR et al (2012) The impact of platelet transfusion characteristics on posttransfusion platelet increments and clinical bleeding in patients with hypoproliferative thrombocytopenia. Blood 119:5553-5562

114. Slichter SJ, Davis K, Enright H, Braine H, Gernsheimer T et al (2005) Factors affecting posttransfusion platelet increments, platelet refractoriness, and platelet transfusion intervals in thrombocytopenic patients. Blood 105:4106-4114

115. Inverardi D, Bocchio C, Rossi L, Mazzucco L, De Paoli L et al (2002) Clinical, immunologic, and technical factors affecting recovery of platelet count after platelet transfusion. Haematologica 87:893-894

116. Hitzler WE (2014) [Single-donor (apheresis) platelets and pooled whole-blood-derived platelets-significance and assessment of both blood products]. Clin Lab 60:1-39
117. Heuft HG, Mende W, Blasczyk R (2008) A general change of the platelet transfusion policy from apheresis platelet concentrates to pooled platelet concentrates is associated with a sharp increase in donor exposure and infection rates. Transfus Med Hemother 35:106-113

118. Arzneimittelgesetz: Gesetz über den Verkehr mit Arzneimitteln; (Arzneimittelgesetz-AMG); in der Fassung der Bekanntmachung des Gesetzes vom 12. Dezember 2005 (BGBI. I S. 3394), Bundesanzeiger-Verlag

119. Arzneimittel- und Wirkstoffherstellungsverordnung vom 3. November 2006 (BGBI. I S. 2523), die zuletzt durchArtikel 1 der Verordnung vom 28. Oktober 2014 (BGBI. I S. 1655) geändert worden ist

120. Transfusionsgesetz - TFG. Gesetz zur Regelung des Transfusionswesens Transfusionsgesetz in der Fassung der Bekanntmachung vom 28. August 2007 (BGBI. I S. 2169), das durch Artikel 12 des Gesetzes vom 17. Juli 2009 (BGBI. I S. 1990) geändert worden ist

121. Arbeitskreis Blut (2013) Aktualisierung der Voten 34 und 35,Verfahren zur Rückverfolgung (Look Back) gemäß § 19 Transfusions gesetz". Bundesgesundheitsbl 56:476-478

122. Wiersum-Osselton JC, van Tilborgh-de Jong AJ, Zijlker-Jansen PY, van de Watering LM, Brand A et al (2013) Variation between hospitals in rates of reported transfusion reactions: is a high reporting rate an indicator of safer transfusion? Vox Sang 104:127-134

123. Henseler $O$, Heiden $M$, Haschberger B, Hesse J, Seitz R (2011) Report on Notifications Pursuant to section sign21 German Transfusion Act for 2008 and 2009. Transfus Med Hemother 38:199216

124. Henseler $\mathrm{O}$, Heiden $M$, Haschberger B, Hesse J, Seitz R (2013) [Report on notifications pursuant to section sign21 German Transfusion Act for 2010 and 2011]. Bundesgesundheitsblatt Gesundheitsforschung Gesundheitsschutz 56:1352-1367

125. Offergeld R, Ritter S, Hamouda O (2012) [HIV, $\mathrm{HCV}, \mathrm{HBV}$ and syphilis surveillance among blood donors in Germany 2008-2010]. Bundesgesundheitsblatt Gesundheitsforschung Gesundheitsschutz 55:907-913

126. Pietersz RN, Engelfriet CP, Reesink HW, Wood EM, Winzar S et al (2007) Detection of bacterial contamination of platelet concentrates. Vox Sang 93:260-277

127. Hillyer $C D$, Josephson $C D$, Blajchman MA, Vostal JG, Epstein JS et al (2003) Bacterial contamination of blood components: risks, strategies, and regulation: joint ASH and AABB educational session in transfusion medicine. Hematology Am Soc Hematol Educ Program 2003:575-589

128. Yomtovian R, Lazarus HM, Goodnough LT, Hirschler NV, Morrissey AM et al (1993) A prospective microbiologic surveillance program to detect and prevent the transfusion of bacterially contaminated platelets. Transfusion 33:902-909

129. Leiby DA, Kerr KL, Campos JM, Dodd RY (1997) A retrospective analysis of microbial contaminants in outdated random-donor platelets from multiple sites. Transfusion 37:259-263

130. AuBuchon JP, Cooper LK, Leach MF, Zuaro DE, Schwartzman JD (2002) Experience with universal bacterial culturing to detect contamination of apheresis platelet units in a hospital transfusion service. Transfusion 42:855-861 
131. Ness $P$, Braine $H$, King $K$, Barrasso C, Kickler T et al (2001) Single-donor platelets reduce the risk of septic platelet transfusion reactions. Transfusion 41:857-861

132. Kuehnert MJ, Roth VR, Haley NR, Gregory KR, Elder KV et al (2001) Transfusion-transmitted bacterial infection in the United States, 1998 through 2000. Transfusion 41:1493-1499

133. Perez P, Salmi LR, Follea G, Schmit JL, de Barbeyrac B et al (2001) Determinants of transfusion-associated bacterial contamination: results of the French BACTHEM Case-Control Study. Transfusion 41:862-872

134. Mohr H, Bayer A, Gravemann U, Muller TH (2006) Elimination and multiplication of bacteria during preparation and storage of buffy coat-derived platelet concentrates. Transfusion 46:949-955

135. Larsen CP, Ezligini F, Hermansen NO, KjeldsenKragh J (2005) Six years' experience of using the BacT/ALERT system to screen all platelet concentrates, and additional testing of outdated platelet concentrates to estimate the frequency of falsenegative results. Vox Sang 88:93-97

136. Fang CT, Chambers LA, Kennedy J, Strupp A, Fucci MC et al (2005) Detection of bacterial contamination in apheresis platelet products: American Red Cross experience, 2004. Transfusion 45:1845-1852

137. te Boekhorst PA, Beckers EA, Vos MC, Vermeij $H$, van Rhenen DJ (2005) Clinical significance of bacteriologic screening in platelet concentrates. Transfusion 45:514-519

138. de Korte D, Curvers J, de Kort WL, Hoekstra T, van der Poel CL et al (2006) Effects of skin disinfection method, deviation bag, and bacterial screening on clinical safety of platelet transfusions in the Netherlands. Transfusion 46:476-485

139. Munksgaard L, Albjerg L, Lillevang ST, GahrnHansen B, Georgsen J (2004) Detection of bacterial contamination of platelet components: six years' experience with the BacT/ALERT system. Transfusion 44:1166-1173

140. Schrezenmeier $H$, Walther-Wenke $G$, Muller TH, Weinauer F, Younis A et al (2007) Bacterial contamination of platelet concentrates: results of a prospective multicenter study comparing pooled whole blood-derived platelets and apheresis platelets. Transfusion 47:644-652

141. Eder AF, Kennedy JM, Dy BA, Notari EP, Weiss JW et al (2007) Bacterial screening of apheresis platelets and the residual risk of septic transfusion reactions: the American Red Cross experience (2004-2006). Transfusion 47:1134-1142

142. Kleinman SH, Kamel HT, Harpool DR, Vanderpool SK, Custer B et al (2006) Two-year experience with aerobic culturing of apheresis and whole blood-derived platelets. Transfusion 46:17871794

143. Ramirez-Arcos S, Goldman M (2005) Evaluation of pooled cultures for bacterial detection in whole blood-derived platelets. Transfusion 45:12751279

144. Jenkins C, Ramirez-Arcos S, Goldman M, Devine DV (2011) Bacterial contamination in platelets: incremental improvements drive down but do not eliminate risk. Transfusion 51:2555-2565

145. Lee CK, Ho PL, Lee KY, Tsui GT, Chua E et al (2008) Value of anaerobic culture in bacterial surveillance program for platelet concentrates. Transfusion 48:2606-2611

146. Perez P, Bruneau C, Chassaigne M, Salmi LR, Noel $L$ et al (2002) Multivariate analysis of determinants of bacterial contamination of whole-blood donations. Vox Sang 82:55-60
147. McDonald CP, Lowe P, Roy A, Robbins S, Hartley S et al (2001) Evaluation of donor arm disinfection techniques. Vox Sang 80:135-141

148. Robillard P, Nawej K, Delage G (2005) Platelet bacterial contaminations and effectiveness of diverting the first $40 \mathrm{mls}$ at whole blood donation for whole-blood collections. Transfusion 45(Suppl):25A

149. de Korte D, Marcelis JH, Verhoeven AJ, Soeterboek AM (2002) Diversion of first blood volume results in a reduction of bacterial contamination for whole-blood collections. Vox Sang 83:13-16

150. Walther-Wenke G, Wirsing von Konig CH, Daubener W, Heiden M, Hoch J et al (2011) Monitoring bacterial contamination of blood components in Germany: effect of contamination reduction measures. Vox Sang 100:359-366

151. Funk MB, Lohmann A, Guenay S, Henseler O, Heiden $M$, et al. (2011) Transfusion-Transmitted Bacterial Infections - Haemovigilance Data of German Blood Establishments (1997-2010). Transfus Med Hemother 38:266-271

152. Eder AF, Dy BA, Kennedy JM, Notari I, Edward P et al (2008) The American Red Cross donor hemovigilance program: complications of blood donation reported in 2006. Transfusion 48:1809-1819

153. Burkhart J, Wittmann G, Howe J, Michel P, Schramm W et al (2005) Klebsiella pneumoniae in platelet concentrates-a case report. Transf Med Hemother 32:64

154. Sireis W, Ruster B, Daiss C, Hourfar MK, Capalbo G et al (2011) Extension of platelet shelf life from 4 to 5 days by implementation of a new screening strategy in Germany. Vox Sang 101:191-199

155. Vollmer T, Engemann J, Kleesiek K, Dreier J (2011) Bacterial screening by flow cytometry offers potential for extension of platelet storage: results of 14 months of active surveillance. Transfus Med 21:175-182

156. Schreiber GB, Busch MP, Kleinman SH, Korelitz JJ (1996) The risk of transfusion-transmitted viral infections. The Retrovirus Epidemiology Donor Study. N Engl J Med 334:1685-1690

157. Busch MP, Glynn SA, Stramer SL, Strong DM, Caglioti $S$ et al (2005) A new strategy for estimating risks of transfusion-transmitted viral infections based on rates of detection of recently infected donors. Transfusion 45:254-264

158. Hourfar MK, Jork C, Schottstedt V, Weber-Schehl M, Brixner V et al (2008) Experience of German Red Cross blood donor services with nucleic acid testing: results of screening more than $30 \mathrm{Mio}$ blood donations for human immunodeficiency virus-1, hepatitis $C$ virus, and hepatitis $B$ virus. Transfusion 48:1558-1566

159. Seed CR, Cheng A, Ismay SL, Bolton WV, Kiely P et al (2002) Assessing the accuracy of three viral risk models in predicting the outcome of implementing HIV and HCV NAT donor screening in Australia and the implications for future HBV NAT. Transfusion 42:1365-1372

160. Offergeld R, Faensen D, Ritter S, Hamouda $O$ (2005) Human immunodeficiency virus, hepatitis $C$ and hepatitis $B$ infections among blood donors in Germany 2000-2002: risk of virus transmission and the impact of nucleic acid amplification testing. Euro Surveill 10:8-11

161. Offergeld R, Ritter $S$, Faensen D, Hamouda O (2005) HIV, HCV, HBV and syphilis infections among blood donors in Germany 20032004. Report of the Robert Koch Institute in accordance with Article 22 of the Transfusion Act. Bundesgesundheitsblatt Gesundheitsforschung Gesundheitsschutz 48:1273-1287
162. Yasui $Y$, Yanai $H$, Sawanpanyalert $P$, Tanaka $H$ (2002) A statistical method for the estimation of window-period risk of transfusion-transmitted $\mathrm{HIV}$ in donor screening under non-steady state. Biostatistics 3:133-143

163. an der Heiden M, Ritter S, Hamouda O, Offergeld $\mathrm{R}$ (2015) Estimating the residual risk for HIV, HCV and HBV in different types of platelet concentrates in Germany. Vox Sang 108:123-130

164. Offergeld R, Ritter S, Kamp C, Hamouda O, an der Heiden M (2012) Differences in infection risks between pool and apheresis platelets - a mathematic model. Transfus Med Hemother 39(S1):36

165. RKI (2013) Virushepatitis B und D im jahr 2013. Epide Bull 2014 30:259-270

166. RKI (2014) HIV-Infektionen und AIDS-Erkrankungen in Deutschland. Epide Bull 2014 26:213-232

167. RKI (2014) Virushepatitis C: Situationsbericht Deutschland 2013. Epide Bull 31:276-284

168. Ritter S, Hamouda O, Offergeld R (2012) Demography and donation frequencies of blood and plasma donor populations in Germany. Update 2010 and 5-year comparison. Bundesgesundheitsblatt Gesundheitsforschung Gesundheitsschutz 55:914-922

169. Offergeld R, Ritter S, Quabeck L, Hamouda $O$ (2010) Epidemiological data on infections among blood donors in Germany 2007. Bundesgesundheitsblatt Gesundheitsforschung Gesundheitsschutz 53:1188-1196

170. Willand L, Ritter S, Reinhard B, Offergeld R, Hamouda O (2008) HIV, HCV, HBV and syphilis infections among blood donors in Germany 2006. Report from the Robert Koch Institute in accordance with Article 22 of the Transfusion Act. Bundesgesundheitsblatt Gesundheitsforschung Gesundheitsschutz 51:902-914

171. Ghani AC, Ferguson NM, Donnelly CA, Hagenaars TJ, Anderson RM (1998) Estimation of the number of people incubating variant CJD. Lancet 352:1353-1354

172. Ghani AC, Ferguson NM, Donnelly CA, Anderson RM (2000) Predicted vCJD mortality in Great Britain. Nature 406:583-584

173. Ghani AC, Donnelly CA, Ferguson NM, Anderson RM (2003) Updated projections of future vCJD deaths in the UK. BMC Infect Dis 3:4

174. Hewitt PE, ljaz S, Brailsford SR, Brett R, Dicks S et al (2014) Hepatitis E virus in blood components: a prevalence and transmission study in southeast England. Lancet 384(9956):1766-1773

175. Thiele T, Heddle N, Greinacher A (2013) Donor exposures in recipients of pooled platelet concentrates. N Engl J Med 368:487-489

176. Huzly D, Umhau M, Bettinger D, Cathomen T, Emmerich $\mathrm{F}$ et al (2014) Transfusion-transmitted hepatitis E in Germany, 2013. Euro Surveill 19 :pii=20812

177. Seltsam A (2011) Pathogenreduktion von Blutprodukten, ein Paradigmenwechsel in der Transfusionsmedizin. Hämotherapie 17:26-34

178. Osman A, Hitzler WE, Meyer CU, Landry P, Corduan $A$ et al (2014) Effects of pathogen reduction systems on platelet microRNAs, mRNAs, activation, and function. Platelets 26:154-163

179. Gesundheit. MdABdBf (2008) Reduktion des Septikämierisikos bei der Anwendung von Thrombozytenkonzentraten. Bundesgesundheitsbl 51:1485-1487

180. Kaufman RM, Assmann SF, Triulzi DJ, Strauss RG, Ness P et al (2015) Transfusion-related adverse events in the Platelet Dose study. Transfusion 55:144-153 
181. Bönig H, Müller M (2011) Donor safety comes first. Vox Sang 101:175-175

182. McLeod B, Price T, Owen H, Ciavarella D, Sniecinski l et al (1998) Frequency of immediate adverse effects associated with apheresis donation. Transfusion 38:938-943

183. Wiltbank TB, Giordano GF (2007) The safety profile of automated collections: an analysis of more than 1 million collections. Transfusion 47:10021005

184. Leitman SF, Boltansky H, Alter HJ, Pearson FC, Kaliner MA (1986) Allergic reactions in healthy platelet-pheresis donors caused by sensitization to ethylene oxide gas. N Engl J Med 315:1192-1196

185. Buchta C, Bittner C, Höcker P, Macher M, Schmid $R$ et al (2003) Donor exposure to the plasticizer di (2-ethylhexyl) phthalate during plateletpheresis. Transfusion 43:1115-1120

186. Bolan CD, Leitman SF (2002) Management of anticoagulation-associated toxicity during large-volume leukapheresis of peripheral blood stem cell donors. Blood 99:1878-1878

187. Charney DI, Salmond R (1990) Cardiac arrest after hypertonic citrate anticoagulation for chronic hemodialysis. ASAIO Trans 36:M217-M219

188. Schrezenmeier H, Seifried E (2011) The ethics of wasting the donor's gift of buffy coat: response to EC Vamvakas. Vox Sang 100:258-259

189. http://www.pei.de/DE/infos/meldepflichtige/meldung-blutprodukte-21-transfusionsgesetz/berichte/berichte-21tfg-node. html\#doc3258776bodyText1. Zugegriffen: 15. Mai 2015 